Supporting Information for

\title{
Highly Fluorescent Gold Cluster Assembly
}

Hogeun Chang,,$^{\dagger,+\perp}$ Niladri S. Karan,,$^{\dagger,+, \pm}$ Kwangsoo Shin, ${ }^{\dagger \dagger, \perp}$ Megalamane. S. Bootharaju, ${ }^{\dagger,}$ Sanghee Nah, ${ }^{\S}$ Sue In Chae, ${ }^{\dagger, \dagger}$ Woonhyuk Baek, ${ }^{\dagger, \dagger}$ Sanghwa Lee, ${ }^{\dagger, \ddagger}$ Junhee Kim, ${ }^{\dagger, \dagger}$ Young Ju Son, ${ }^{\dagger,}$ Taegyu Kang, ${ }^{\dagger, \ddagger}$ Giho Ko, ${ }^{\dagger, \star}$ Seung-Hae Kwon, ${ }^{\S}$ and Taeghwan Hyeon ${ }^{*},, \star \star$

$\dagger$ Center for Nanoparticle Research, Institute for Basic Science (IBS), Seoul 08826, Republic of Korea

$\$$ School of Chemical and Biological Engineering, and Institute of Chemical Process, Seoul National University, Seoul 08826, Republic of Korea

$\S$ Seoul Center, Korea Basic Science Institute (KBSI), Seoul 02841, Republic of Korea

${ }^{\perp}$ H. C., N. S. K. and K. S. are equally contributed to this work.

\pm Present address: Department of Chemistry, Asutosh College, Kolkata 700026, India

*e-mail: thyeon@snu.ac.kr (T.H.) 


\section{Table of Contents}

Experimental Materials and Methods........................................................................ S3

Supporting Discussion

Supporting Figures and Tables................................................................................. S7

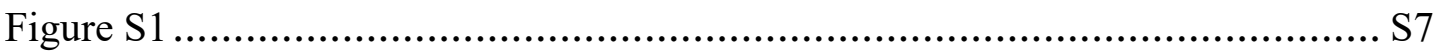

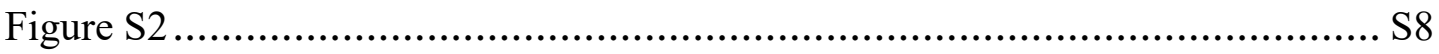

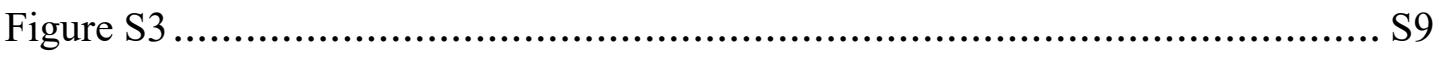

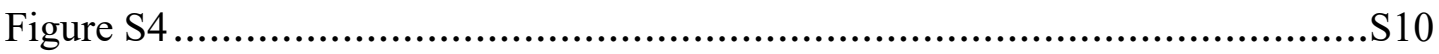

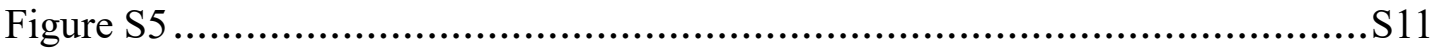

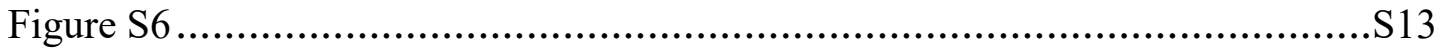

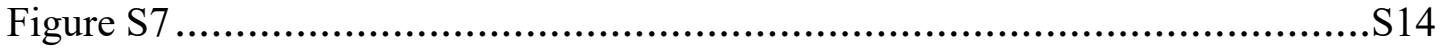

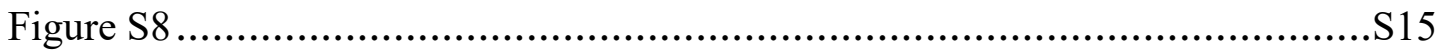

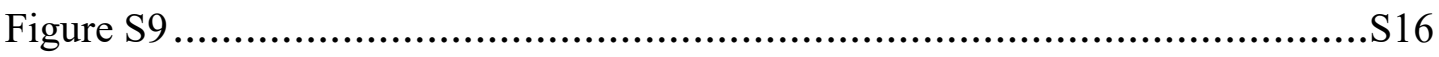

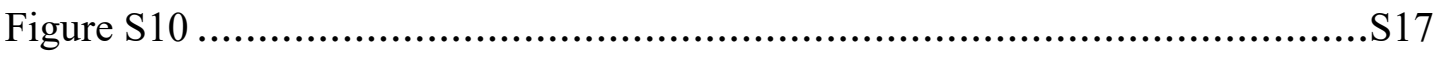

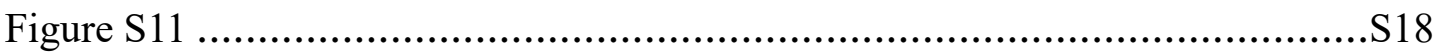

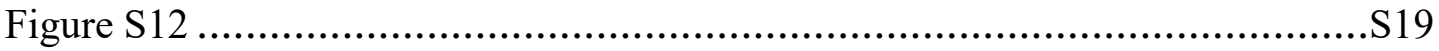

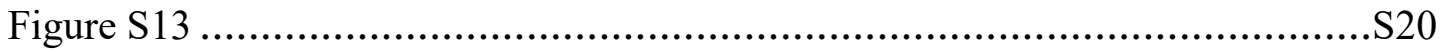

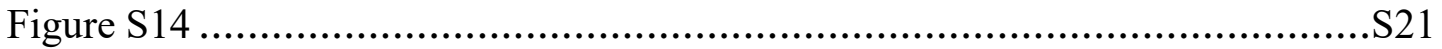

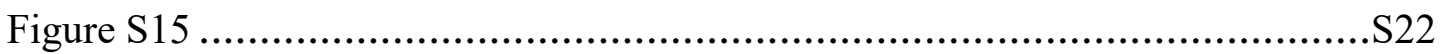

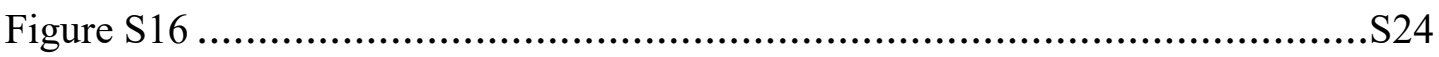

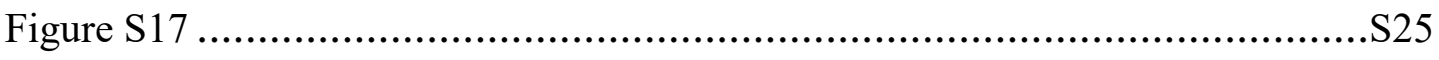

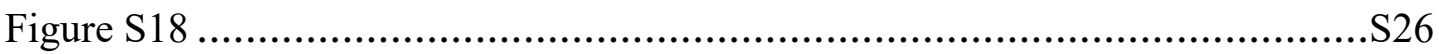

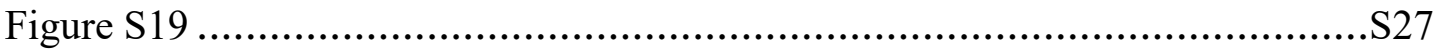

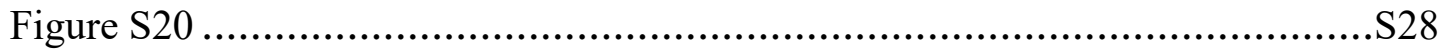

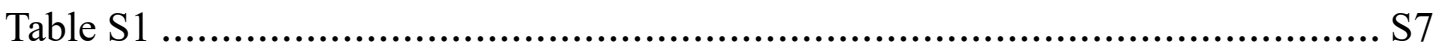

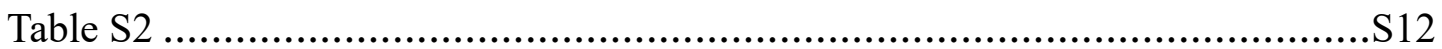

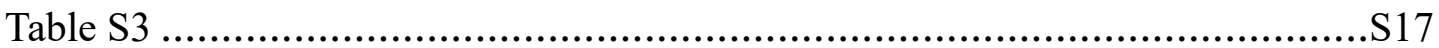

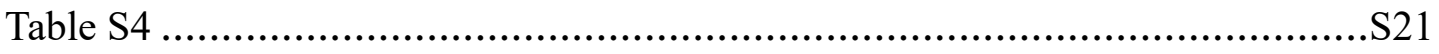

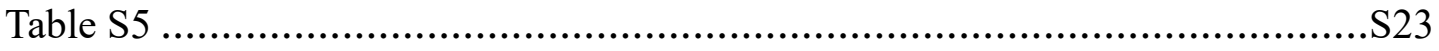

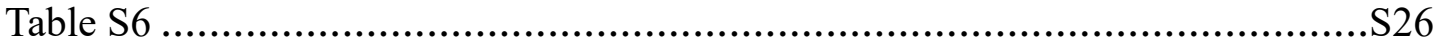

Supporting References ..............................................................................................S28 


\section{Experimental Materials and Methods}

Materials. Hydrogen tetrachloroaurate $\left(\mathrm{HAuCl}_{4} \cdot 3 \mathrm{H}_{2} \mathrm{O} ; 99.8 \%-\mathrm{Au}\right)$ was purchased from Strem Chemicals. 3-mercaptopropionic acid (MPA-H, 99\%), 6-mercaptohexanoic acid (MHA-H; 90\%), 11 -mercaptoundecanoic acid (MUDA-H, 95\%), zinc acetate (99.99\% trace metal basis), cadmium acetate dihydrate $(98 \%)$, calcium acetate hydrate $(99 \%)$, cobalt(II) acetate tetrahydrate (98\%), copper(II) acetate hydrate (98\%), iron(II) acetate (anhydrous, 97\%), manganese(II) acetate tetrahydrate (99\%), 2,5-dihydroxybenzoic acid (DHB), LUDOX ${ }^{\circledR}$ HS40 colloidal silica, ethylenediaminetetraacetic acid disodium salt dehydrate ( $\left.\mathrm{Na}_{2} \mathrm{EDTA}\right)$, and doxorubicin hydrochloride were purchased from Sigma-Aldrich. Sodium hydroxide (98\%) and dimethyl sulfoxide (DMSO, 98\%) were purchased from Samchun Chemicals. All the chemicals were used without further purification.

Synthesis of $\mathrm{Au}_{4}$ (MHA)4 clusters: $7 \mathrm{mg}(0.02 \mathrm{mmol})$ of $\mathrm{HAuCl}_{4} \cdot 3 \mathrm{H}_{2} \mathrm{O}$ was dissolved in $5 \mathrm{~mL}$ deionized water and stirred at $600 \mathrm{rpm}$. Then $100 \mu \mathrm{l}(0.723 \mathrm{mmol}, 36$ molar excess $)$ of MHA$\mathrm{H}$ was added to the aqueous gold solution. The solution changes from transparent yellow to turbid white. After $15 \mathrm{~min}, 1 \mathrm{M} \mathrm{NaOH}$ solution was added dropwise to dissolve the white precipitate, adjusting $\mathrm{pH}$ of the solution to slightly basic (between 8 and 10).

Synthesis of GCAs. $1 \mathrm{ml}$ of $0.1 \mathrm{M}$ aqueous zinc acetate solution was added quickly to transparent $\mathrm{Au}_{4}(\mathrm{MHA})_{4}$ solution. The colorless solution becomes cloudy white and gradually changes to yellowish green after a few hours. During the course of the reaction, the optical properties of the gold clusters were measured.

Disassembly and reassembly of GCAs. 0.5 M EDTA solution was used for metal extraction. To monitor the disassembly process, 3.57 (0.25 equimolar to $\left.\mathrm{Zn}^{2+}\right), 7.14$ (0.50 eq.), 10.7 (0.75 eq.) and $14.3 \mu \mathrm{l}$ ( 1 eq.) of EDTA solution are added to each $0.5 \mathrm{ml}$ crude GCA solution. 14.3 $\mu \mathrm{l}$ of $0.5 \mathrm{M}$ zinc acetate solution was added to induce reassembly of $\mathrm{Au}_{4}(\mathrm{MHA})_{4}$ clusters.

Synthesis of $\mathrm{Au}_{4}(\mathrm{MPA})_{4}, \mathrm{Au}_{4}(\mathrm{MUDA})_{4}$ clusters, and their assembly. The syntheses of $\mathrm{Au}_{4}(\mathrm{MPA})_{4}, \mathrm{Au}_{4}(\mathrm{MUDA})_{4}$ clusters, and their assembly were performed similarly to the MHA case with slight modifications. $7 \mathrm{mg}(0.02 \mathrm{mmol})$ of $\mathrm{HAuCl}_{4} \cdot 3 \mathrm{H}_{2} \mathrm{O}$ was dissolved in $5 \mathrm{~mL}$ of deionized water and stirred at $600 \mathrm{rpm}$. Then $71 \mu \mathrm{l}$ of MPA-H or $158 \mathrm{mg}$ of MUDA-H $(0.723$ mmol, 36 molar excess) was added to the aqueous gold solution. The solution changes from transparent yellow to turbid white. After $15 \mathrm{~min}, 1 \mathrm{M} \mathrm{NaOH}$ solution was added dropwise to dissolve the white precipitate, adjusting the $\mathrm{pH}$ of the solution to slightly basic (between 8 and 10). Similar to the synthesis of GCA, $1 \mathrm{ml}$ of $0.1 \mathrm{M}$ aqueous zinc acetate solution was added quickly to transparent $\mathrm{Au}_{4}(\mathrm{MPA})_{4}$ and $\mathrm{Au}_{4}(\mathrm{MUDA})_{4}$ solutions. Colorless solutions become cloudy white and gradually change to yellowish green after few hours. Notably, the solution becomes gradually turbid and finally shows white precipitate for $\mathrm{Au}_{4}(\mathrm{MUDA})_{4}$ case.

Synthesis of Au-MUDA oligomer and their assembly. The syntheses of Au-MUDA oligomer and their assembly were performed with a slight modification to the MHA case. $7 \mathrm{mg}(0.02$ mmol) of $\mathrm{HAuCl}_{4} .3 \mathrm{H}_{2} \mathrm{O}$ was dissolved in $5 \mathrm{~mL}$ DMSO and stirred at $600 \mathrm{rpm} .158 \mathrm{mg}$ of MUDA-H (0.723 mmol, 36 molar excess) was added to gold dissolved in DMSO. The solution changes from transparent yellow to cloudy white. $1 \mathrm{ml}$ of $0.1 \mathrm{M}$ zinc acetate DMSO solution was added quickly to Au-MUDA oligomer solution and heated to $70{ }^{\circ} \mathrm{C}$. The cloudy white solution gradually changes to yellowish green after a few hours. Whereas Au-MUDA oligomer shows red phosphorescence, Au-MUDA assembly shows greenish-blue fluorescence similar to the cluster assembly synthesized in the aqueous media. 
Synthesis of GCA with different metal ions. $1 \mathrm{ml}$ of $0.1 \mathrm{M}$ aqueous metal $\left(\mathrm{Cd}^{2+}, \mathrm{Ca}^{2+}, \mathrm{Co}^{2+}\right.$, $\left.\mathrm{Cu}^{2+}, \mathrm{Fe}^{2+}, \mathrm{Mn}^{2+}\right)$ acetate solution was added quickly to transparent $\mathrm{Au}_{4}(\mathrm{MHA})_{4}$ solution. $\mathrm{Cd}^{2+}$ was the only case showing distinct photoluminescence.

Mass characterization. Matrix assisted laser desorption/ionization-time of flight (MALDITOF) mass spectrometric data were obtained using Voyager-DETM STR Biospectrometry Workstation manufactured by Applied Biosystems Inc. in National Center for Inter-University Research Facilities (NCIRF), Republic of Korea. Concentrated DHB in methanol was used as a matrix. Pulsed nitrogen laser (337 nm, 3 ns pulses) with the power of $60 \sim 70 \%$ induced desorption and ionization of $\mathrm{Au}$ clusters. $20 \mathrm{kV}$ potential accelerated positive ions after desorption and ionization. Reflector mode is used to acquire detailed mass spectrometry.

Steady state spectroscopy. Steady state absorption data were collected using Agilent technologies Carry Series UV-Vis-NIR spectrophotometer. Steady state and time-resolved PL data were collected using Edinburg FLS980 fluorimeter. Samples were excited with $375 \mathrm{~nm}$ laser light (EPL-375) for time-resolved photoluminescence. The instrument response function (IRF) of the photon counting system was acquired by measuring the scattered light of the diluted LUDOX solution. The absolute quantum yield of samples is measured with an integrating sphere system. The relative photoluminescence quantum yield of GCA samples is measured by using fluorescein in ethanol as the standard $\left(\lambda_{\mathrm{ex}}=425 \mathrm{~nm}, \mathrm{QY}=0.79\right) .{ }^{1}$

X-ray photoelectron spectroscopy. X-ray photoelectron spectroscopy was achieved using Thermo Fisher Scientific ESCALAB 250 at Korea Basic Science Institute (KBSI) Busan center, Republic of Korea.

X-ray absorption spectroscopy. X-ray absorption spectroscopic data were acquired from 10C beamline at Pohang Accelerator Laboratory (PAL), Republic of Korea. Samples were diluted in boron nitride and measured by using fluorescence mode. The spectrum is processed by using Athena of Demeter package. ${ }^{2}$

Dynamic Light Scattering. Hydrodynamic diameters were measured by using Malvern Zetasizer Nano.

Scanning Transmission Electron Microscopy and Energy Dispersive X-ray spectroscopy. STEM imaging was done using JEOL-JEM 2100F/HR instrument operated at $200 \mathrm{kV}$. EDX spectra and elemental mapping were acquired using the attached Oxford EDS system with 80 $\mathrm{mm}^{2}$ detector (Oxford Instruments Analytical Ltd., UK). The sample was prepared by putting a drop of diluted sample on the TEM grid and dried overnight for observation.

Transient absorption spectroscopy. Transient absorption spectroscopy was acquired at KBSI, Seoul. A Yb:KGW amplifier system (Pharos, Light Conversion) generating $1028 \mathrm{~nm}$ pulses at $400 \mathrm{kHz}$ with a pulse duration of $230 \mathrm{fs}$ was split into two beam paths. One portion of the amplifier was used to pump a non-collinear optical parametric amplifier generating $30 \mathrm{fs}$ pump pulses centered at $690 \mathrm{~nm}$. The pump beam was focused on a beta barium borate (BBO) crystal to generate frequency-doubled light centered at $345 \mathrm{~nm}$ which was modulated with a chopper at $2 \mathrm{KHz}$. The other portion of the amplifier was used to activate a collinear optical parametric amplifier generating 230 fs probe pulses. The probe pulses were focused on a BBO crystal to produce laser pulses with energy from 390 to $470 \mathrm{~nm}$. A motorized linear stage in the pump path was used to delay the pump pulse in time relative to the probe pulse. The pump and probe beams were focused on a target solution using a parabolic mirror. The transmitted probe beam was spectrally filtered using filters and detected using a photodetector. The signals were sent to a gated integrator and a lock-in amplifier triggered at a synchronized frequency with a 
chopper. The data acquisition of time-dependent probe intensity changes with pump-on and pump-off events was carried out with a home-built LabView software.

Synthesis and characterization of doxorubicin-loaded GCAs (Dox-GCAs). To incorporate doxorubicin in GCA, $80 \mu \mathrm{l}$ of doxorubicin solution dissolved in DW $(10 \mathrm{mg} / \mathrm{ml})$ were added to $\mathrm{Au}_{4}(\mathrm{MHA})_{4}$ solution $4 \mathrm{~h}$ after the addition of zinc acetate solution. Residual free doxorubicin and excessive mercaptohexanoic acid were removed by centrifugation and resuspended in phosphate buffer saline (PBS). For analysis of release profile, Dox-GCAs were loaded to dialysis device (Slide-A-Lyzer, MINI Dialysis Device, 10kDa MWCO, Thermo-Scientific) with filled with PBS to the outside membrane. The dialysis device was incubated in $37{ }^{\circ} \mathrm{C}$ with slow stirring. Both the solution inside and outside of the dialysis membrane were aliquoted and measured absorbance and fluorescence to calculate the amount of doxorubicin and check the fluorescent intensity of GCA. After $22 \mathrm{~h}$ of slow release, EDTA solution was added to induce disassembly-mediated triggering and monitored it over an extra $48 \mathrm{~h}$.

Cell Culture. HeLa cells (HeLa cell-line, human adenocarcinoma, KCLB-10002) obtained from Korean Cell Line Bank (KCLB, Seoul, Korea) were maintained in Dulbecco's Modified Eagle's Medium (DMEM, Gibco). The medium was supplemented with $10 \%$ fetal bovine serum (FBS, Gibco BRL), $100 \mu \mathrm{g} \mathrm{ml}^{-1}$ streptomycin, and $100 \mathrm{IU}$ penicillin (Gibco BRL). Cells were grown as monolayer cultures in a T75-flask and sub-cultured three times in one week at $37{ }^{\circ} \mathrm{C}$ in an atmosphere containing $5 \% \mathrm{CO}_{2}$ and $100 \%$ relative humidity.

Viability assay. For the in vitro cytotoxicity assay, cells in a logarithmic growth phase were detached and plated (100 $\mu \mathrm{l}$ per well) in 96-well flat-bottom microplates at a density of 10,000 cells per well, which were then left for $24 \mathrm{~h}$ at $37^{\circ} \mathrm{C}$ to resume exponential growth. GCA, DoxGCA, doxorubicin was treated with various concentration. The concentration of doxorubicin was followed by the loading amount of doxorubicin in Dox-GCAs. After $24 \mathrm{~h}$ incubation, the media was exchanged, and their cell viability was assessed by MTT (3-[4,5dimethylthialzol-2yl]-2,5-diphenyltetrazolium bromide, Sigma) assay. The assay was performed in triplicate. The cells were incubated in media with $1 \mathrm{mg} / \mathrm{ml}$ of MTT solution for $2 \mathrm{~h}$. Then the MTT solution was removed, and the precipitated violet crystals were dissolved in $200 \mu$ dimethyl sulfoxide (DMSO). The absorbance of the solution was measured at $490 \mathrm{~nm}$ with a microplate reader (Victor X4, Perkin-Elmer, USA).

Cellular imaging. HeLa cells were detached and plated to a coverslip-bottom dish. After $24 \mathrm{~h}$ incubation, the plate was washed plate with PBS before GCAs treatment. The Dox-GCAs suspended in PBS were treated to the cell. After 10 min incubation, cellular media were replaced with Draq5 containing DMEM. A confocal laser scanning microscope (LSM 780, Carl-Zeiss, Germany) was used to obtain live cell time-lapse fluorescent imaging with a stable incubating system. 


\section{Supporting Discussion}

Comparison among GCA, Au NC and NP by TA pump fluence dependence. The second (50 60 ps) and third (>100 ps) decays in TA are mainly designated as the combination of the vibrational relaxation and the radiative recombination at the vibrational unrelaxed state from the pump fluence dependence in TA and correlative TRPL of GCAs. The pump fluence dependency of the transient dynamics has been used to examine the elusive boundary between nonmetallic Au NCs and Au NPs. ${ }^{3,4}$ The decay rate of nonmetallic Au NCs are independent to the pump fluence, but plasmonic gold NPs are known to show slower decay rate with stronger pump power, because the higher electron temperature (or the electron density containing higher energy) of electron induced by higher pump fluence delays the rate of electron-phonon coupling in a metal lattice. Interestingly, GCAs show pump fluence dependent decay; however, their biexponential decays are accelerated by increasing pump fluence. This phenomenon strengthens the structural uniqueness of GCAs as the structure of GCAs without metal core can be supported by the absence of the electron-phonon interaction. 


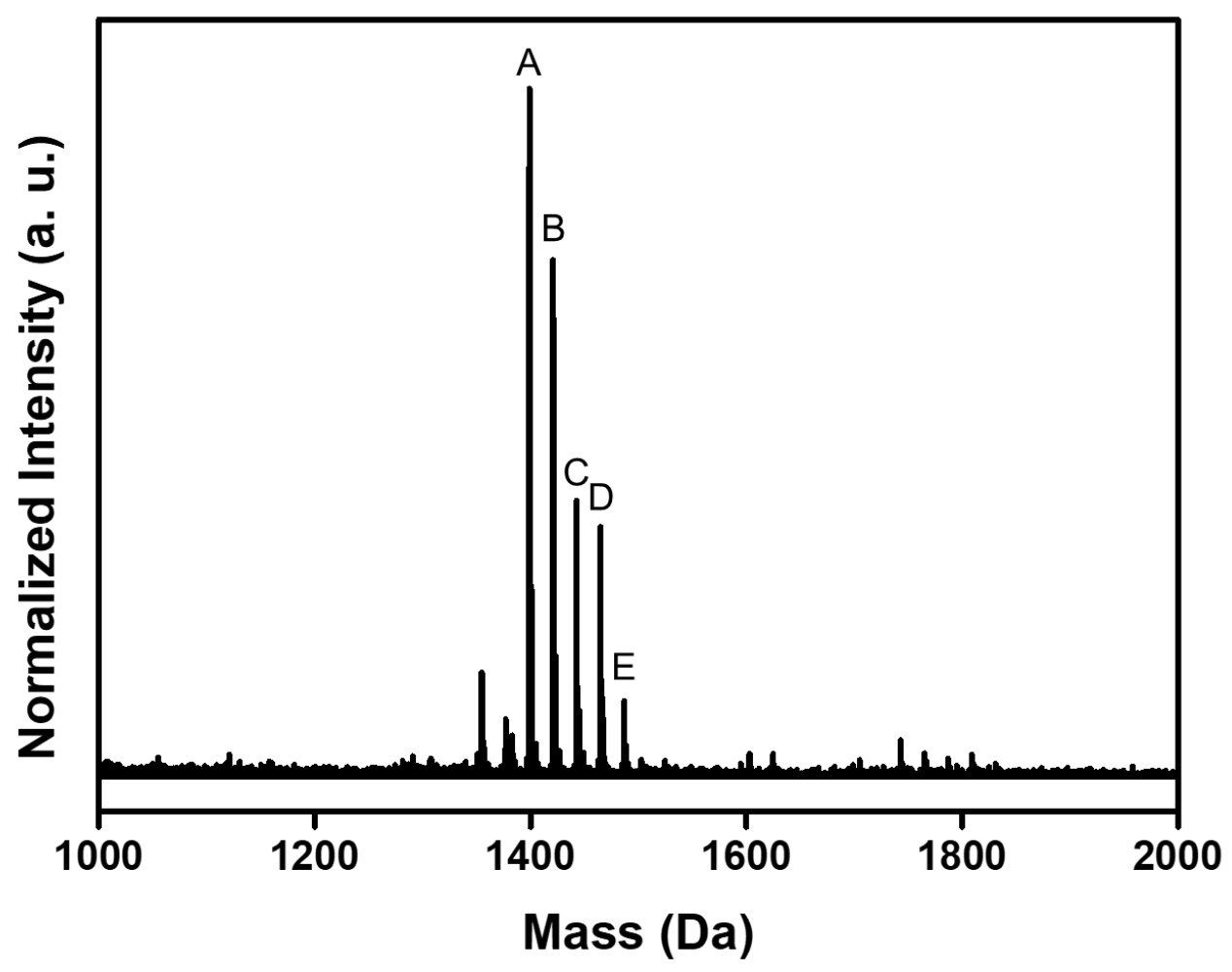

Figure S1. Full spectrum of Au4(MHA)4 clusters. Labelled peaks are assigned in Table S1.

Table S1. Calculated mass formula of labelled peaks in Figure S1.

\begin{tabular}{|c|c|c|}
\hline Label & Maximum mass (Da) & Formula \\
\hline A & 1399.05 & {$\left[\mathrm{Au}_{4}\left(\mathrm{SC}_{5} \mathrm{H}_{10} \mathrm{COOH}\right)_{4}+\mathrm{Na}\right]^{+}$} \\
\hline B & 1421.03 & {$\left[\mathrm{Au}_{4}\left(\mathrm{SC}_{5} \mathrm{H}_{10} \mathrm{COOH}\right)_{4}+2 \mathrm{Na}-\mathrm{H}\right]^{+}$} \\
\hline C & 1443.01 & {$\left[\mathrm{Au}_{4}\left(\mathrm{SC}_{5} \mathrm{H}_{10} \mathrm{COOH}\right)_{4}+3 \mathrm{Na}-2 \mathrm{H}\right]^{+}$} \\
\hline D & 1464.99 & {$\left[\mathrm{Au} 4\left(\mathrm{SC}_{5} \mathrm{H}_{10} \mathrm{COOH}\right)_{4}+4 \mathrm{Na}-3 \mathrm{H}\right]^{+}$} \\
\hline E & 1486.98 & {$\left[\mathrm{Au} 4\left(\mathrm{SC}_{5} \mathrm{H}_{10} \mathrm{COOH}\right)_{4}+5 \mathrm{Na}-4 \mathrm{H}\right]^{+}$} \\
\hline
\end{tabular}


a

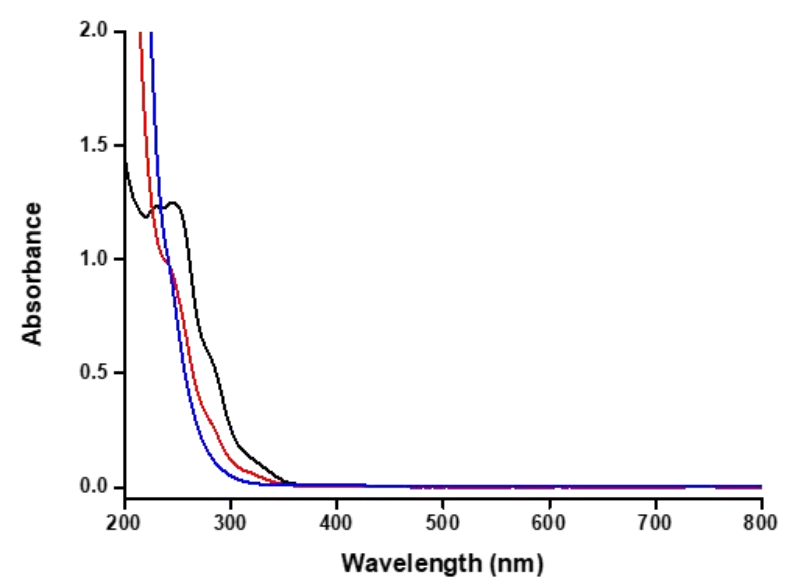

b
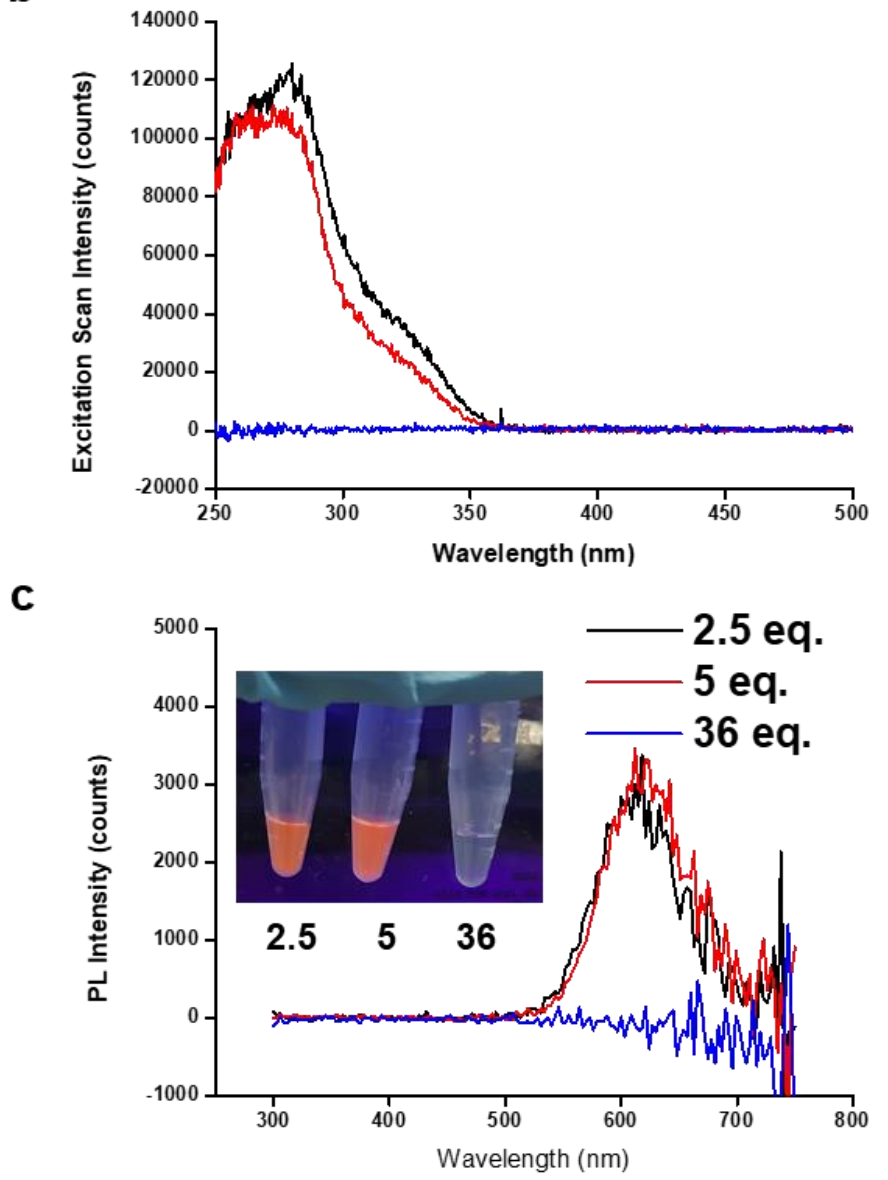

Figure S2. The effect of metal to ligand ratio on the formation of Au-MHA oligomer at $\mathbf{p H}=\mathbf{1 0}$. (a) UV-Vis absorbance, (b) Excitation scan intensity $\left(\lambda_{\mathrm{em}}=600 \mathrm{~nm}\right)$, and (c) PL intensity $\left(\lambda_{\mathrm{ex}}=250 \mathrm{~nm}\right.$ ) of the complexes with Au:MHA ratio of 1:2.5 (black), 1:5 (red), and 1:36 (blue). (c, inset) photograph showing red phosphorescence for Au:MHA ratio of 1:2.5 and 1:5 cases (oligomeric Au-MHA complexes), but no emission for 1:36 case ( $\left.\mathrm{Au}_{4}(\mathrm{MHA})_{4}\right)$. 

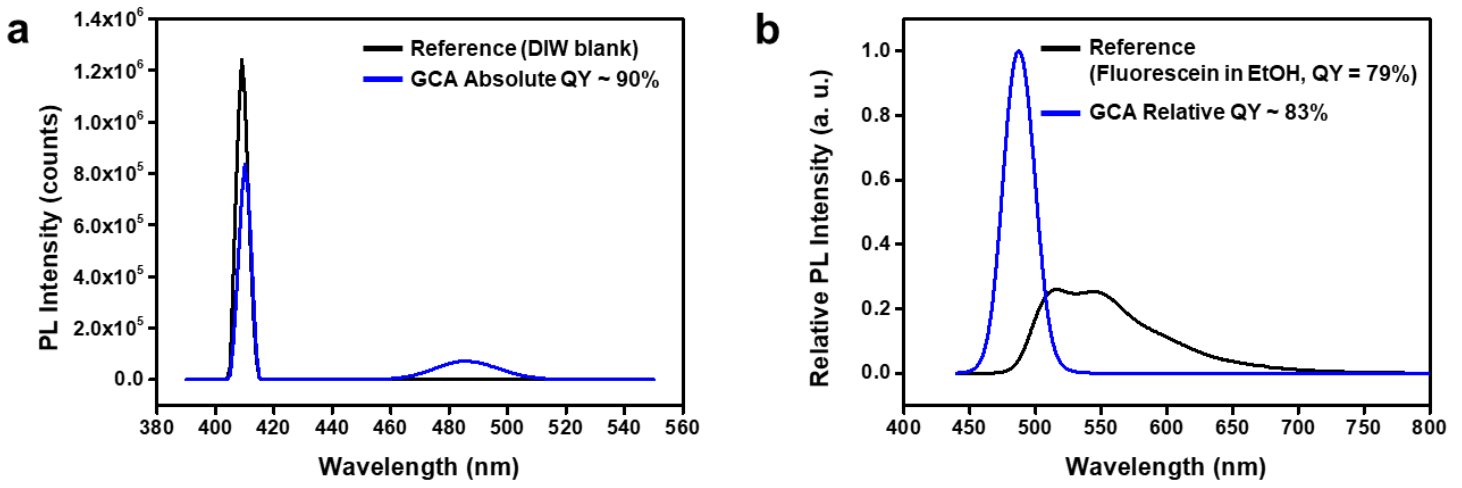

Figure S3. Absolute and relative quantum yield measurement of GCA by using (a) integrating sphere method and (b) reference fluorescein. 


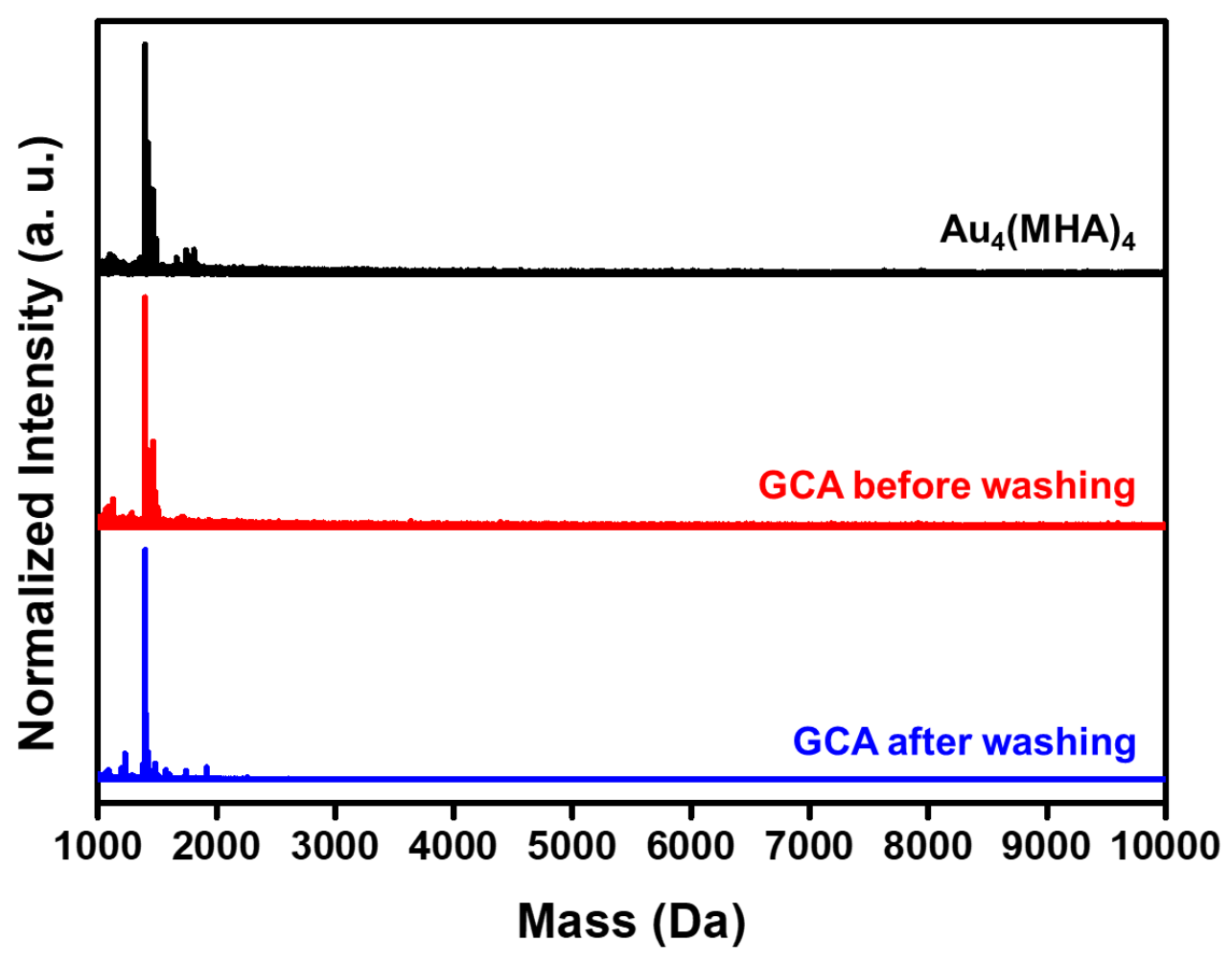

Figure S4. MALDI-TOF mass spectra acquired during GCA formation before $\mathrm{Zn}^{2+}$ addition (black), after $\mathrm{Zn}^{2+}$ addition before washing (red) and after washing (blue). The peak from $\mathrm{Au}_{4}(\mathrm{MHA})_{4}$ is sustained during the entire processes. 


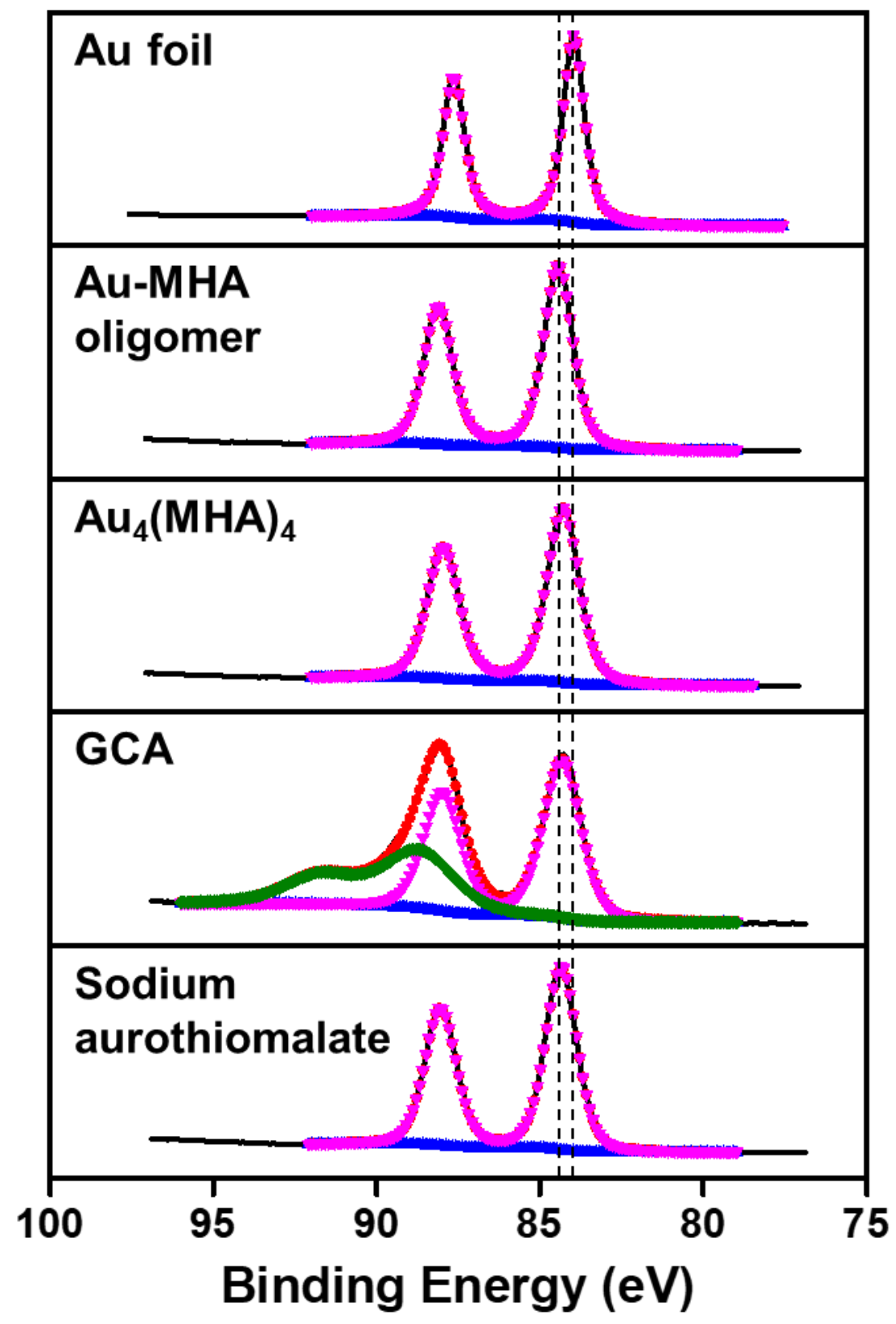

Figure S5. Au $4 \mathrm{f}$ XPS fitting result of Au-MHA oligomer, Au4(MHA)4 cluster, GCA, and references $\left(\mathrm{Au}^{0}\right.$ foil and sodium aurothiomalate). $\mathrm{Au}^{+}$oxidation state is unchanged during reaction process (magenta). Notably, XPS of GCA contains information from $\mathrm{Zn} 3 p$ state (green). 
Table S2. Au 4f XPS fitting parameters in Figure S5.

\begin{tabular}{|c|cccc|}
\hline Sample & Peak position & Area & FWHM & Assign \\
\hline Au foil & $84.0 \mathrm{eV}$ & 2229458.0 & $0.8 \mathrm{eV}$ & $\mathrm{Au}^{0}$ \\
\hline Au-MHA oligomer & $84.4 \mathrm{eV}$ & 202879.5 & $1.1 \mathrm{eV}$ & $\mathrm{Au}^{+}$ \\
\hline $\mathrm{Au}_{4}(\mathrm{MHA})_{4}$ & $84.3 \mathrm{eV}$ & 229444.6 & $1.2 \mathrm{eV}$ & $\mathrm{Au}^{+}$ \\
\hline \multirow{2}{*}{ GCA } & $84.3 \mathrm{eV}$ & 54586.0 & $1.4 \mathrm{eV}$ & $\mathrm{Au}^{+}$ \\
\cline { 2 - 5 } & $88.7 \mathrm{eV}$ & 31640.1 & $2.6 \mathrm{eV}$ & $\mathrm{Zn}^{2+}$ \\
\hline Sodium aurothiomalate & $84.3 \mathrm{eV}$ & 264200.9 & $1.2 \mathrm{eV}$ & $\mathrm{Au}^{+}$ \\
\hline
\end{tabular}




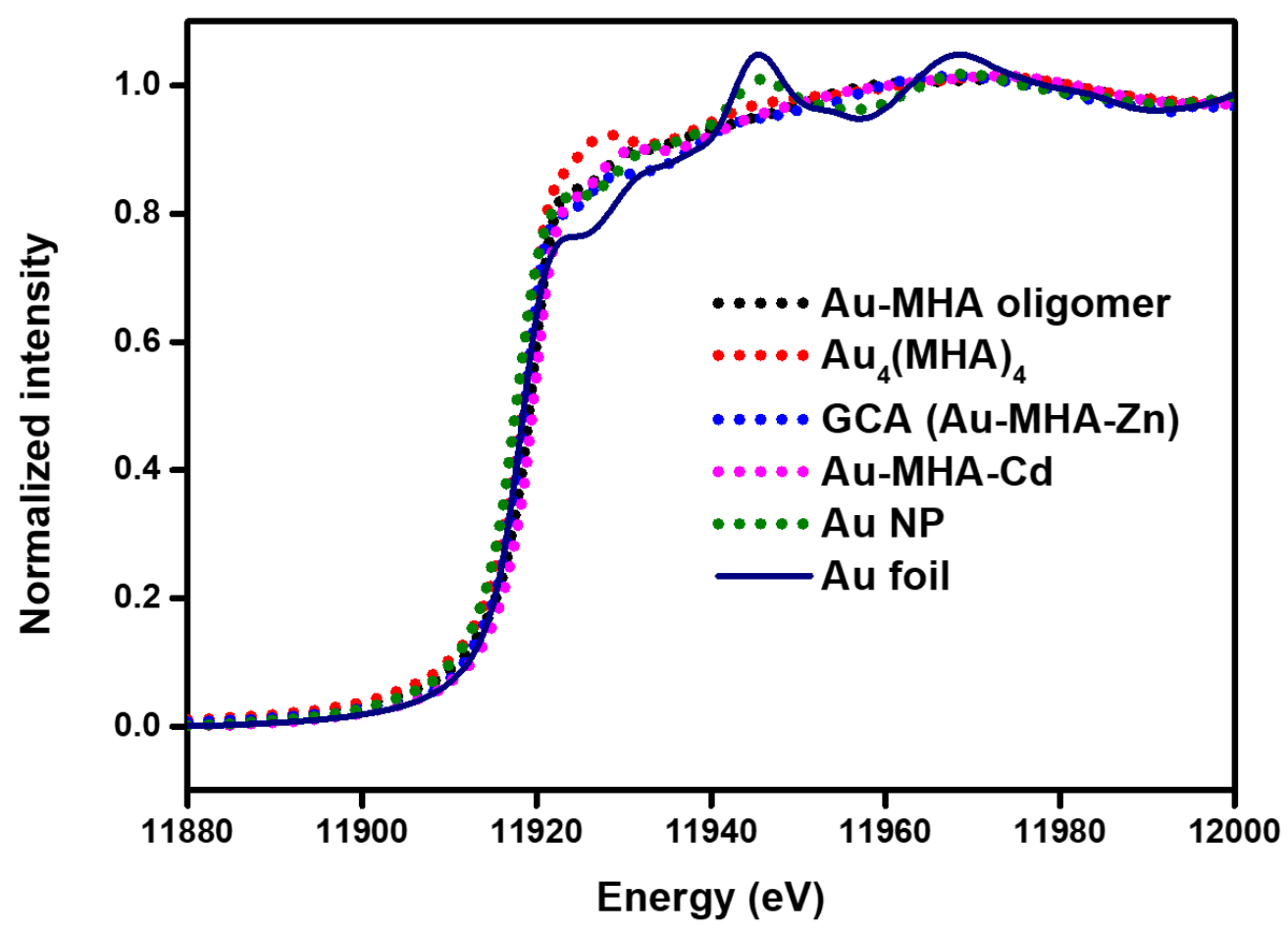

Figure S6. XANES spectra of Au-MHA oligomer, Au4(MHA)4 cluster, GCA, Au-MHA-Cd and references ( $\mathbf{A u}^{\mathbf{0}}$ foil and $\mathrm{Au}$ nanoparticle). The result shows the distinctly oxidized state of $\mathrm{Au}-\mathrm{MHA}$ complex, $\mathrm{Au}_{4}(\mathrm{MHA})_{4}$, and GCA are sustained compared to $\mathrm{Au}(0)$ foil. 

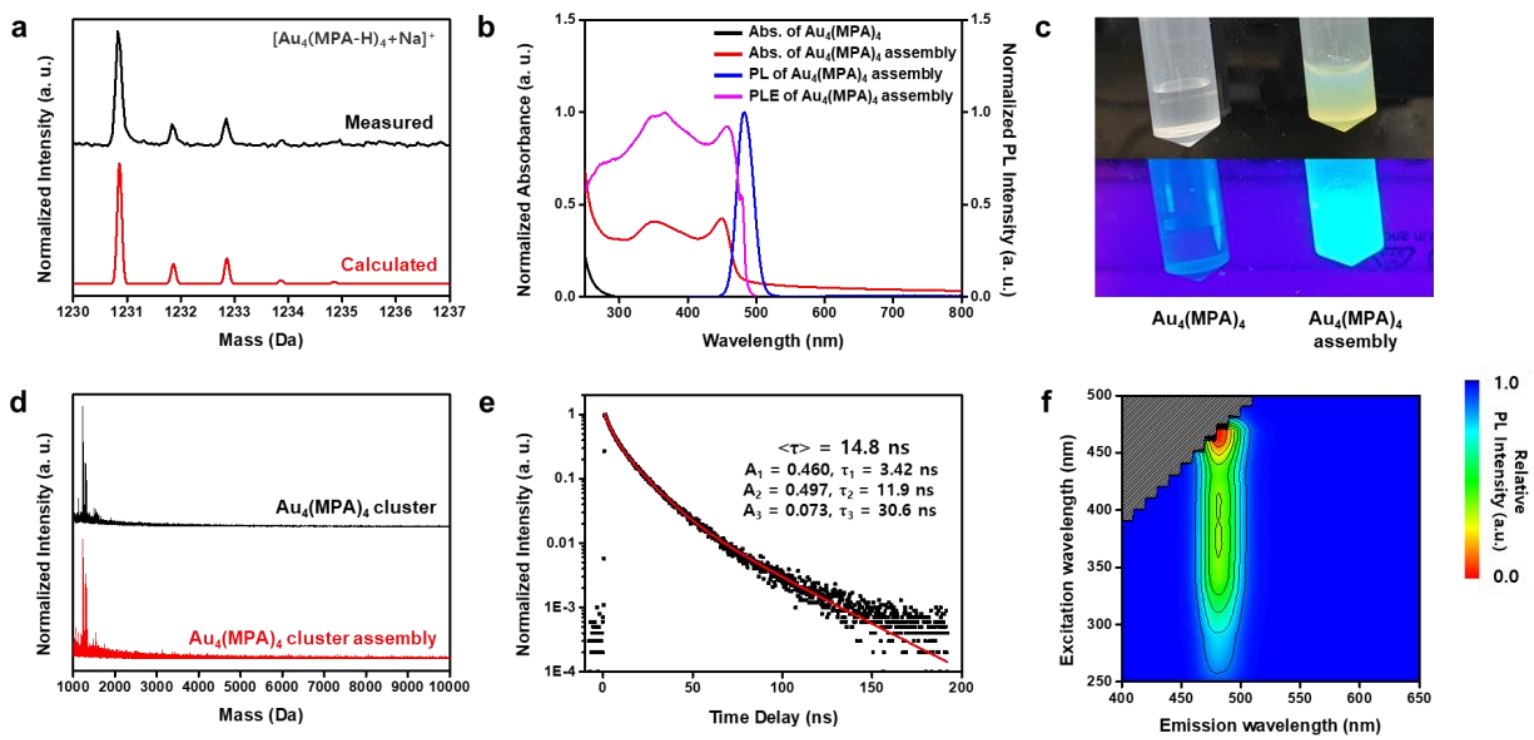

Figure S7. Characterization of fluorescent $\mathrm{Au}_{4}(\mathrm{MPA})_{4}$ cluster assembly in aqueous medium. (a) Experimental (black) and calculated (red) mass spectra of $\mathrm{Au}_{4}(\mathrm{MPA})_{4}$ cluster. (b) Change of absorption spectra before (black) and after $\mathrm{Zn}^{2+}$ ion addition (red) and PL (blue, $\lambda_{\mathrm{ex}}$ $=365 \mathrm{~nm}$ ), and PLE of $\mathrm{Au}_{4}(\mathrm{MPA})_{4}$ cluster assembly (magenta, $\lambda_{\mathrm{em}}=480 \mathrm{~nm}$ ). (c) Photographs taken with visible light (top) and with UV light (bottom) before and after $\mathrm{Zn}^{2+}$ ion addition. (d) MALDI-TOF mass spectra acquired during $\mathrm{Au}_{4}(\mathrm{MPA})_{4}$ cluster assembly formation before (black) and after $\mathrm{Zn}^{2+}$ addition (red). (e) TRPL of $\mathrm{Au}_{4}(\mathrm{MPA})_{4}$ cluster assembly $\left(\lambda_{\mathrm{em}}=480 \mathrm{~nm}\right.$ ). (f) Excitation-emission contour mapping of $\mathrm{Au}_{4}(\mathrm{MPA})_{4}$ cluster assembly showing its single emissive channel. 

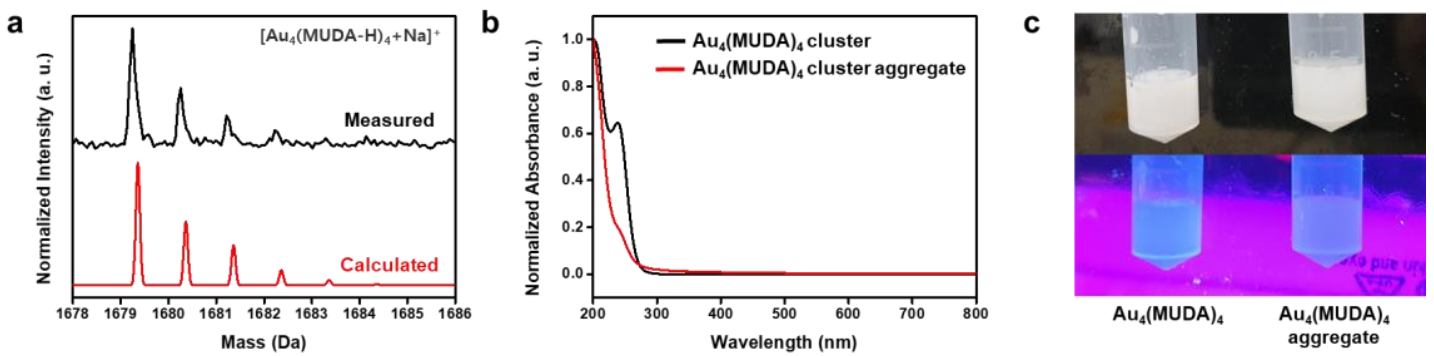

Figure S8. Characterization of fluorescent $\mathrm{Au}_{4}(\mathrm{MUDA})_{4}$ cluster assembly in aqueous medium. (a) Experimental (black) and calculated (red) mass spectra of Au4(MUDA) 4 cluster. (b) Change of absorption spectra before (black) and after $\mathrm{Zn}^{2+}$ ion addition (red). No characteristic absorption features are observed after $\mathrm{Zn}^{2+}$ addition. (c) Photographs taken under visible light (top) and with UV light (bottom) before and after $\mathrm{Zn}^{2+}$ ion addition. $\mathrm{Au}_{4}(\mathrm{MUDA})_{4}$ clusters are precipitated within a few hours and do not show any emission before and after $\mathrm{Zn}^{2+}$ addition. 

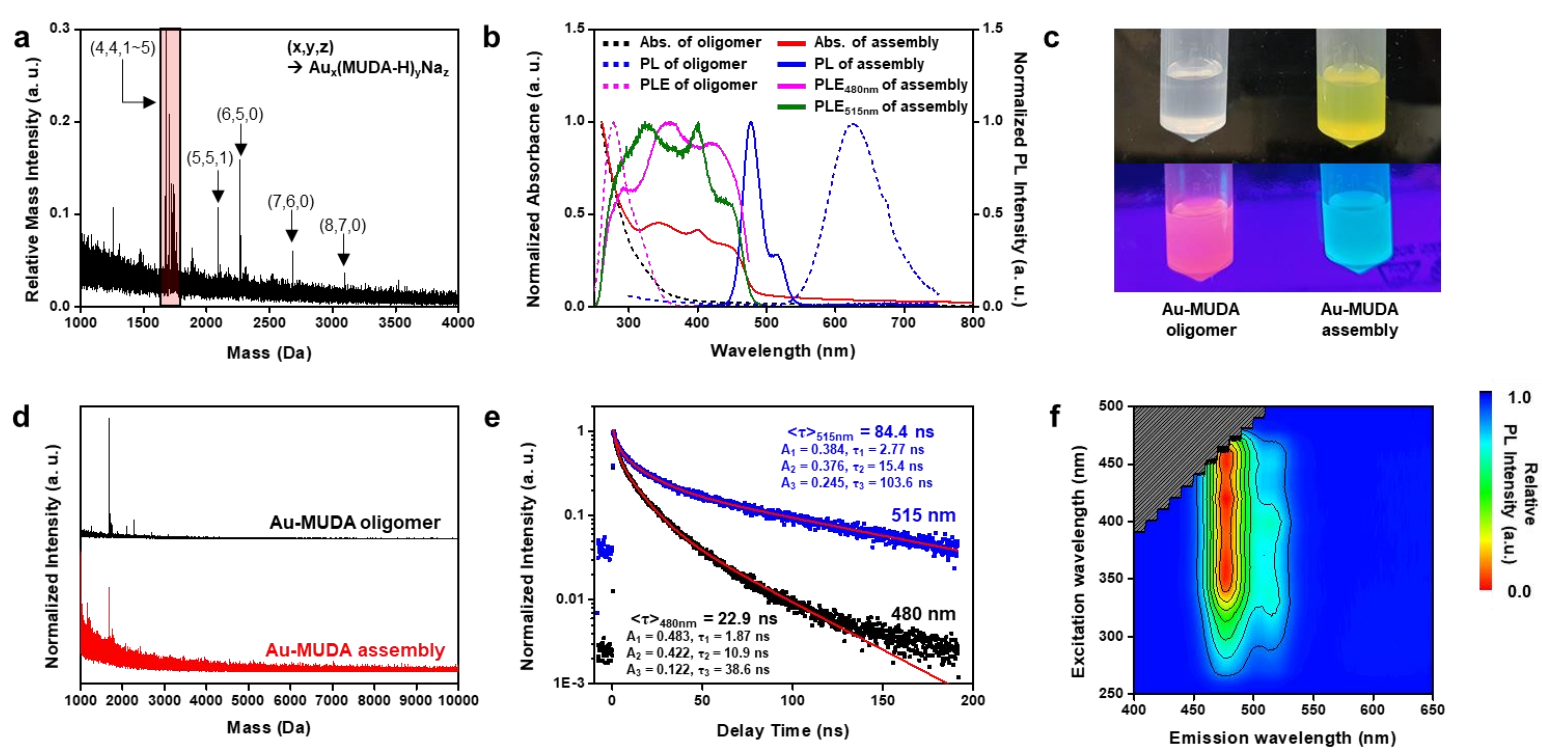

Figure S9. Characterization of fluorescent Au-MUDA assembly in DMSO. (a) Experimental mass spectra of Au-MUDA oligomer. (b) Change of absorption spectra, PL and PLE before (absorption: black dash; PL: blue dash, $\lambda_{\mathrm{ex}}=280 \mathrm{~nm}$; PLE: magenta dash, $\lambda_{\mathrm{em}}=$ $625 \mathrm{~nm}$ ) and after $\mathrm{Zn}^{2+}$ ion addition (absorption: red line; PL: blue line, $\lambda_{\mathrm{ex}}=370 \mathrm{~nm}$; PLE: magenta and green line, $\lambda_{\mathrm{em}}=480,515 \mathrm{~nm}$ ) and PLE of Au-MUDA assembly (magenta, $\lambda_{\mathrm{em}}=$ $625 \mathrm{~nm}$ ). Two distinct peaks can be observed from Au-MUDA assembly. (c) Photographs taken with visible light (top) and with UV light (bottom) before and after $\mathrm{Zn}^{2+}$ ion addition. Blue PL of Au-MUDA assembly can be discriminated from the red PL of Au-MUDA oligomer. (d) MALDI-TOF mass spectra acquired during Au-MUDA assembly formation before (black) and after $\mathrm{Zn}^{2+}$ addition (red). (e) TRPL of Au-MUDA assembly $\left(\lambda_{\mathrm{em}}=480,515 \mathrm{~nm}\right)$. (f) Excitationemission contour mapping of Au-MUDA assembly showing its multiple emissive channels. 

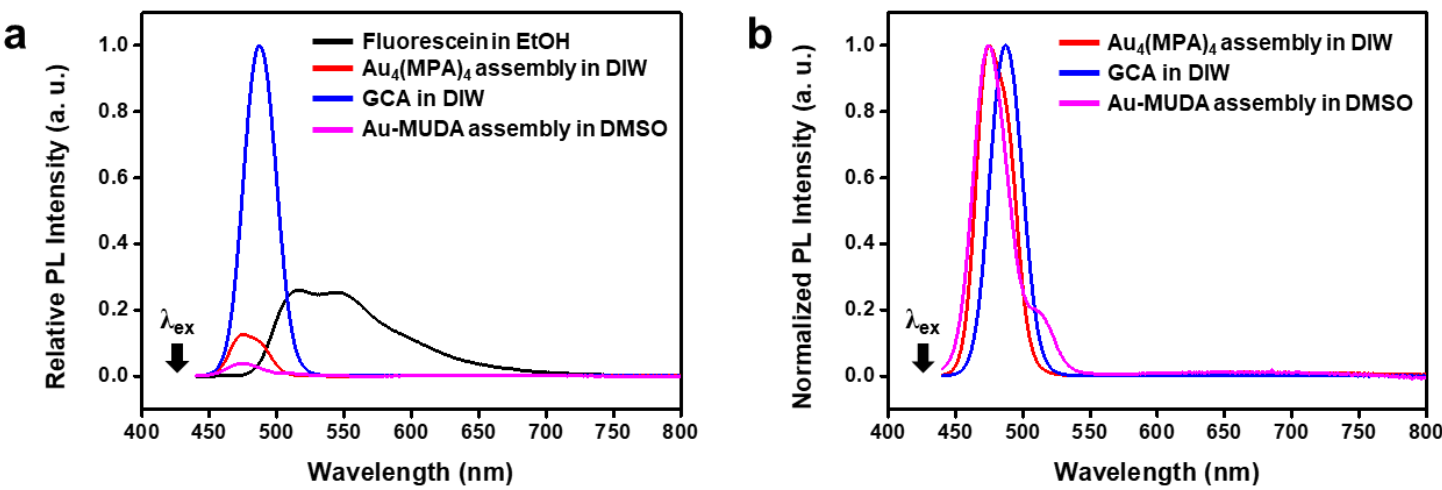

Figure S10. Comparison of PL spectra among Au4(MPA)4 cluster assembly, GCA, AuMUDA assembly, and fluorescein (reference). (a) relative PL intensity, (b) normalized PL intensity.

Table S3. PLQY of Au4(MPA)4 assembly, GCA, and Au-MUDA assembly.

\begin{tabular}{|c|c|c|c|}
\hline Samples & $\begin{array}{c}\text { Absorbance } \\
\text { at } 425 \mathrm{~nm}\end{array}$ & PL area & $\begin{array}{c}\text { Quantum } \\
\text { Yield }\end{array}$ \\
\hline Fluorescein in EtOH & 0.0644 & 33375733 & 0.790 \\
\hline $\mathrm{Au}_{4}$ (MPA) $_{4}$ assembly in DIW & 0.1211 & 9809737 & 0.118 \\
\hline GCA in DIW & 0.0608 & 34488977 & 0.827 \\
\hline Au-MUDA assembly in DMSO & 0.0855 & 2337081 & 0.034 \\
\hline
\end{tabular}



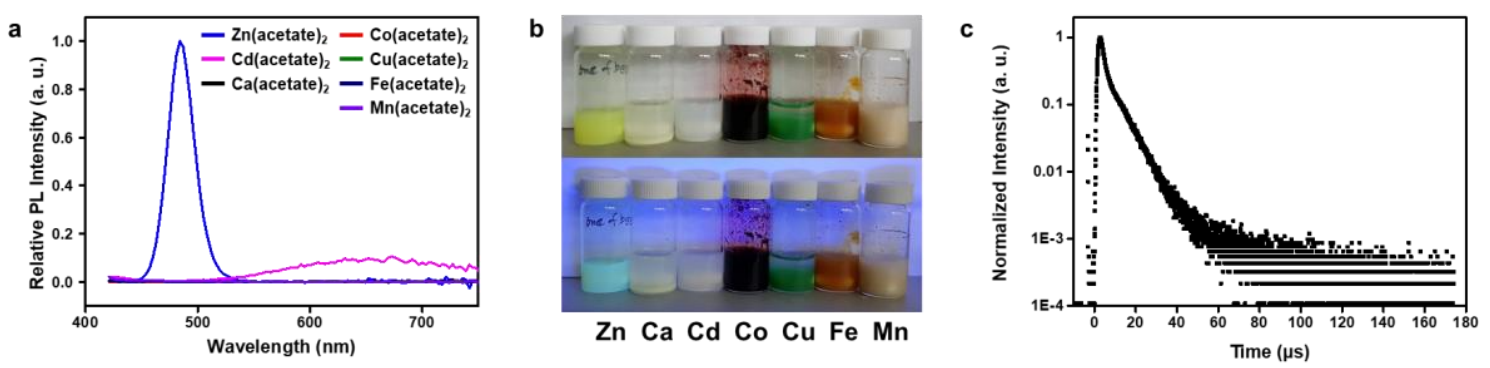

Figure S11. (a) PL spectra and (b) photograph showing the effect of various metal ions on Au4(MHA)4 cluster assembly. (c) TRPL of $\mathrm{Cd}^{2+}$ ion-induced assembly showing phosphorescence. $\mathrm{Cd}^{2+}$ ion-induced assembly shows a weak red emission, but other metal ions induce precipitation without any emission. 


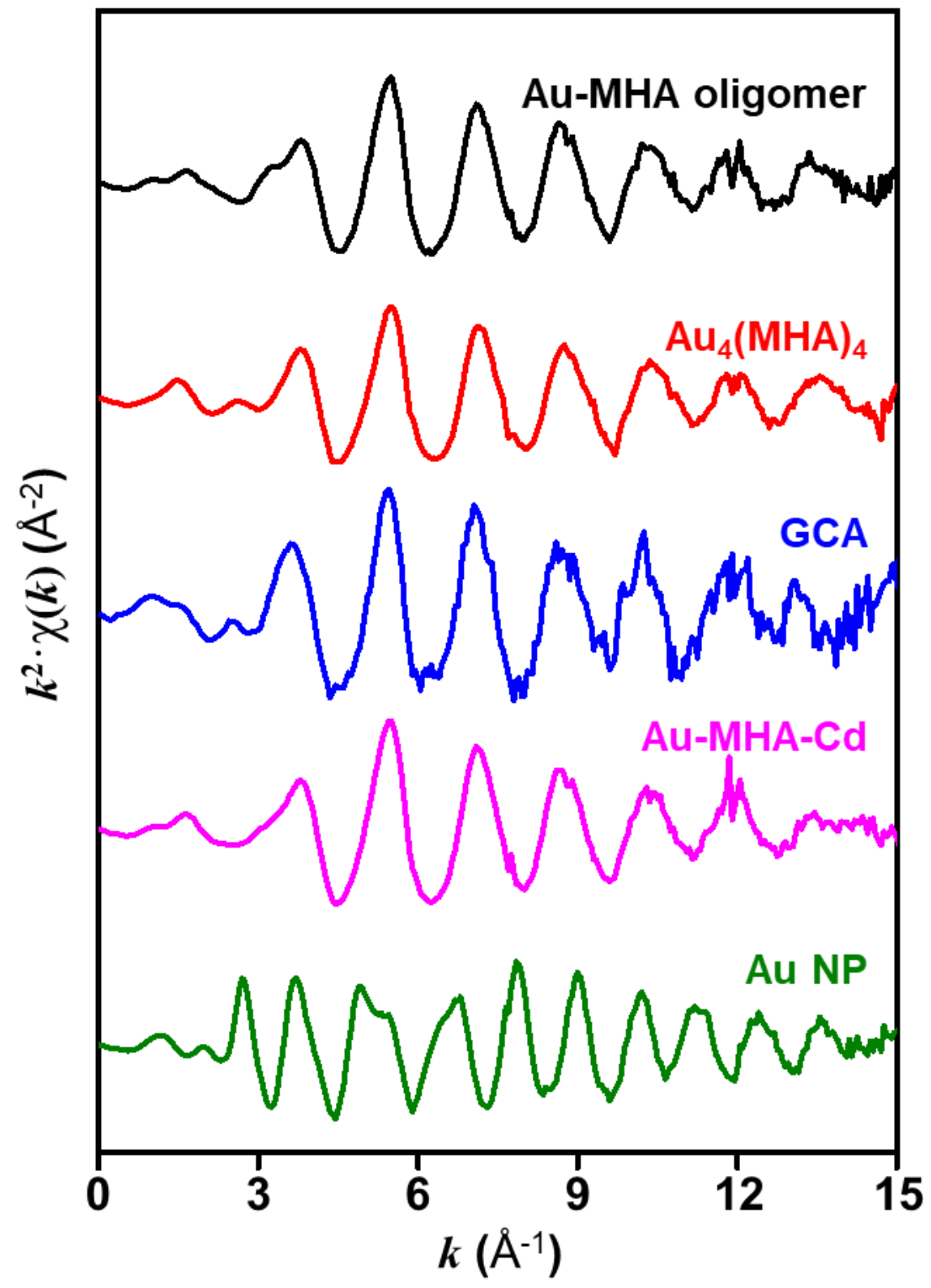

Figure S12. $\boldsymbol{k}^{2}$-weighted Au Lz-edge EXAFS k-range of spectra of Au-MHA oligomer (black), Au4(MHA)4 (red), GCA (blue), Au-MHA-Cd (magenta), and Au nanoparticle (green). 


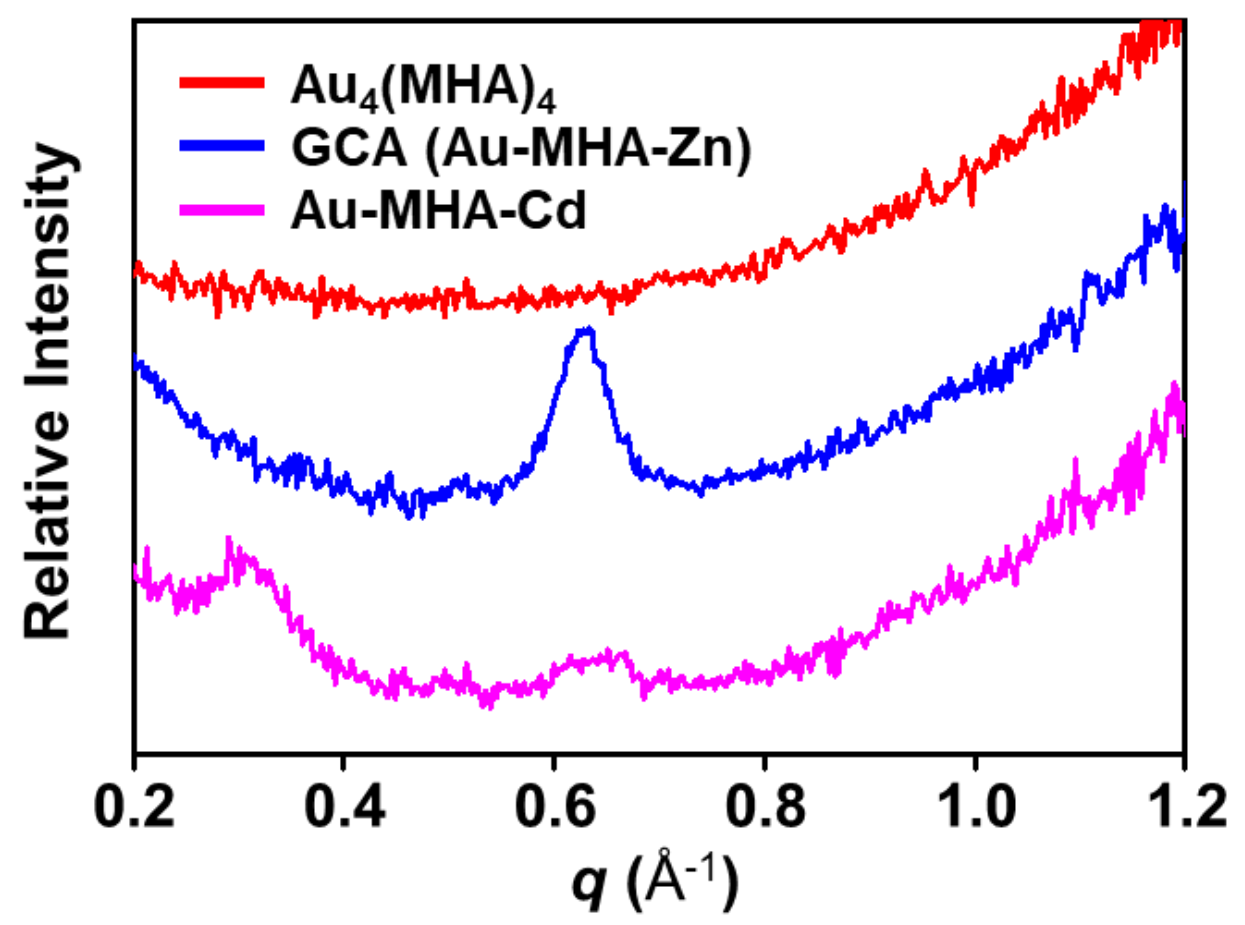

Figure S13. X-ray scattering result of $\mathrm{Au}_{4}(\mathrm{MHA}) 4$, GCA and Au-MHA-Cd dissolved in water. Repetitive structural spacing is observed after metal ion induced assembly. Interestingly, $\mathrm{Zn}^{2+}$-induced assembly (GCA) show much shorter spacing compared to that of $\mathrm{Cd}^{2+}$-induced assembly (Au-MHA-Cd). 


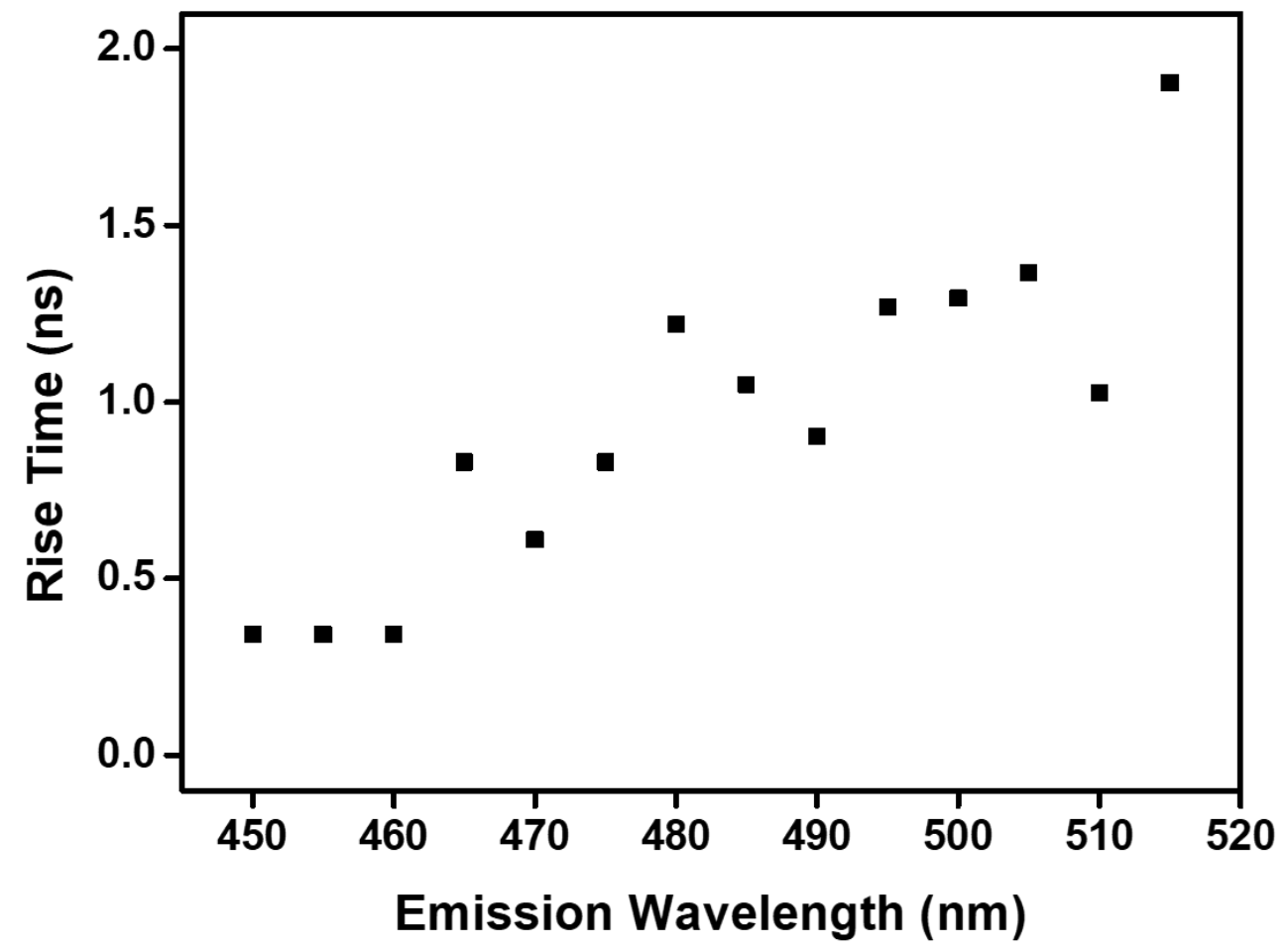

Figure S14. The change of rise time (time delay at the start of decay, $x_{0}$ of fitting result in Table S2) of emission of GCA. For clearance, the time delay at the first rise of TRPL from noise is set as time zero.

Table S4. Fitting parameters of TRPL in Figure 3a.

\begin{tabular}{|c|ccccccccc|}
\hline Wavelength & $\mathbf{X}_{\mathbf{0}}$ & $\mathbf{A}_{\mathbf{0}}$ & $\boldsymbol{\tau}_{\mathbf{0}}$ & $\mathbf{A}_{\mathbf{1}}$ & $\boldsymbol{\tau}_{\mathbf{1}}$ & $\mathbf{A}_{\mathbf{2}}$ & $\boldsymbol{\tau}_{\mathbf{2}}$ & $\mathbf{A}_{\mathbf{3}}$ & $\boldsymbol{\tau}_{\mathbf{3}}$ \\
\hline $\mathbf{4 5 0} \mathbf{~ \mathbf { m }}$ & 0.342 & 0.368 & 0.068 & 0.218 & 2.622 & 0.292 & 22.491 & 0.121 & 105.155 \\
$\mathbf{4 5 5} \mathbf{~ n m}$ & 0.342 & 0.104 & 0.070 & 0.273 & 2.349 & 0.431 & 20.533 & 0.191 & 83.960 \\
$\mathbf{4 6 0} \mathbf{~ n m}$ & 0.342 & 0.105 & 0.070 & 0.242 & 2.594 & 0.454 & 20.512 & 0.198 & 72.781 \\
$\mathbf{4 6 5} \mathbf{~ n m}$ & 0.830 & & & 0.198 & 2.926 & 0.560 & 20.580 & 0.242 & 64.709 \\
$\mathbf{4 7 0} \mathbf{~ n m}$ & 0.610 & & & 0.202 & 4.337 & 0.620 & 23.396 & 0.179 & 66.702 \\
$\mathbf{4 7 5} \mathbf{~ n m}$ & 0.830 & & & 0.171 & 5.552 & 0.684 & 24.187 & 0.145 & 66.987 \\
$\mathbf{4 8 0} \mathbf{~ n m}$ & 1.221 & & & & & 0.596 & 16.018 & 0.404 & 43.442 \\
$\mathbf{4 8 5} \mathbf{~ n m}$ & 1.050 & & & & & 0.677 & 17.736 & 0.323 & 45.562 \\
$\mathbf{4 9 0} \mathbf{~ n m}$ & 0.903 & & & & & 0.776 & 19.422 & 0.224 & 51.234 \\
$\mathbf{4 9 5} \mathbf{~ n m}$ & 1.270 & & & & & 0.830 & 20.164 & 0.170 & 57.386 \\
$\mathbf{5 0 0} \mathbf{~ n m}$ & 1.294 & & & & & 0.904 & 21.619 & 0.096 & 79.290 \\
$\mathbf{5 0 5} \mathbf{~ n m}$ & 1.367 & & & & & 0.931 & 22.120 & 0.069 & 111.417 \\
$\mathbf{5 1 0} \mathbf{~ n m}$ & 1.025 & & & & & 0.943 & 22.457 & 0.057 & 169.571 \\
$\mathbf{5 1 5} \mathbf{~ n m}$ & 1.904 & & & & & 0.928 & 21.636 & 0.072 & 185.379 \\
\hline
\end{tabular}


a

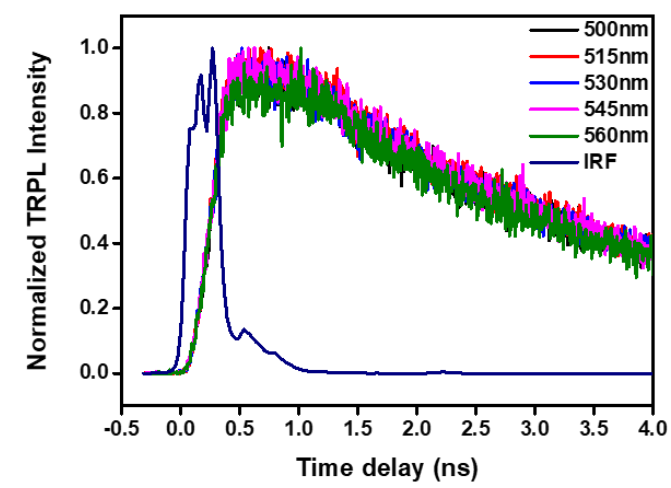

C

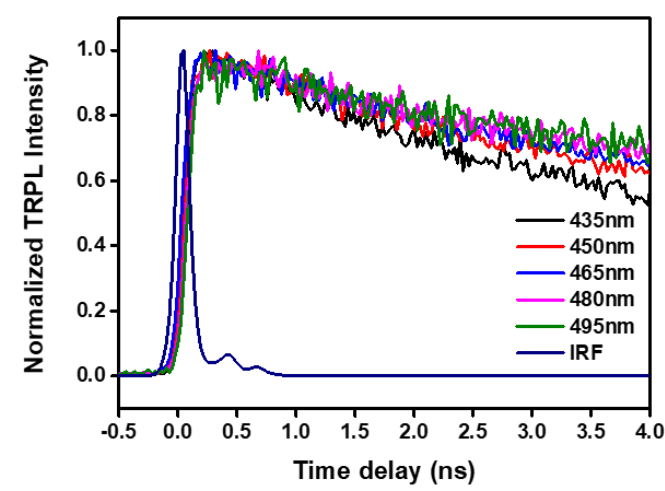

b

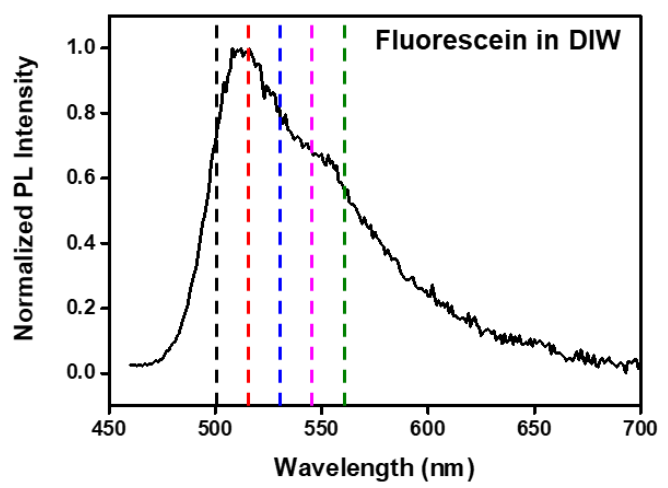

d

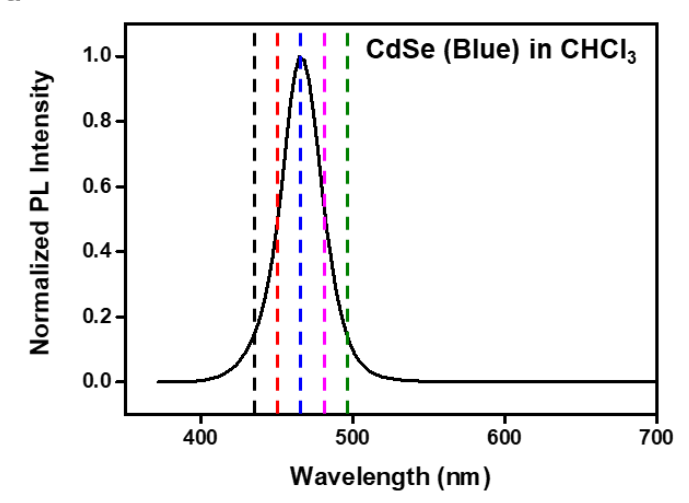

Figure S15. TRPL decay and PL spectra of (a, b) fluorescein dye and (c, d) CdSe QD, showing rise time independence to emission wavelength. 
Table S5. Fitting parameters of normalized TA in Figure 3c. Each lifetime is assigned by its time scale. (I, purple) $\tau<1$ ps component is ascribed to internal conversion and vibrational relaxation from $\mathrm{S}_{2}$ to $\mathrm{S}_{1}$ state. (II, green) $1 \mathrm{ps}<\tau<10$ ps component come from solvent induced relaxation. (III, orange) $10 \mathrm{ps}<\tau<100 \mathrm{ps}$ component can be assigned to the early radiative decay at vibrational unrelaxed state. (IV, red) $\tau>100 \mathrm{ps}$ component is ascribed to the combination of delayed vibrational relaxation process and radiative decay at semi-relaxed state. (V, blue) $\tau>10$ ns component can be understood as radiative recombination at vibrational relaxed excited state.

\begin{tabular}{|c|c|c|c|c|c|c|c|c|}
\hline Wavelength & $\mathbf{A}_{1}$ & $\tau_{1}$ & $\mathbf{A}_{2}$ & $\tau_{2}$ & $\mathbf{A}_{3}$ & $\tau_{3}$ & $\mathbf{A}_{4}$ & $\tau_{4}$ \\
\hline $400 \mathrm{~nm}$ & 1.41 & $332 \mathrm{fs}$ & -0.875 & $7.12 \mathrm{ps}$ & -0.169 & $349 \mathrm{ps}$ & & \\
\hline $410 \mathrm{~nm}$ & 2.08 & $327 \mathrm{fs}$ & -0.665 & $15.0 \mathrm{ps}$ & -0.254 & 909 ps & & \\
\hline $420 \mathrm{~nm}$ & 2.09 & $463 \mathrm{fs}$ & -0.379 & 29.0 ps & -0.506 & $>10 \mathrm{~ns}$ & & \\
\hline $435 \mathrm{~nm}$ & 0.458 & $(29.7 \mathrm{fs})$ & 0.778 & 6.48 ps & -0.236 & $1.80 \mathrm{~ns}$ & & \\
\hline $440 \mathrm{~nm}$ & 0.536 & $4.04 \mathrm{ps}$ & 0.403 & 60.1 ps & 1.01 & $8.39 \mathrm{~ns}$ & -0.951 & $>10 \mathrm{~ns}$ \\
\hline $450 \mathrm{~nm}$ & 0.357 & $6.58 \mathrm{ps}$ & 0.342 & 57.6 ps & 0.260 & $1.28 \mathrm{~ns}$ & 0.0466 & $>10 \mathrm{~ns}$ \\
\hline $460 \mathrm{~nm}$ & 0.398 & 12.0 ps & 0.221 & 49.8 ps & 0.205 & 436 ps & 0.188 & $>10 \mathrm{~ns}$ \\
\hline $470 \mathrm{~nm}$ & 0.0937 & $6.25 \mathrm{ps}$ & 0.432 & 55.4 ps & 0.229 & 925 ps & 0.209 & $>10 \mathrm{~ns}$ \\
\hline
\end{tabular}



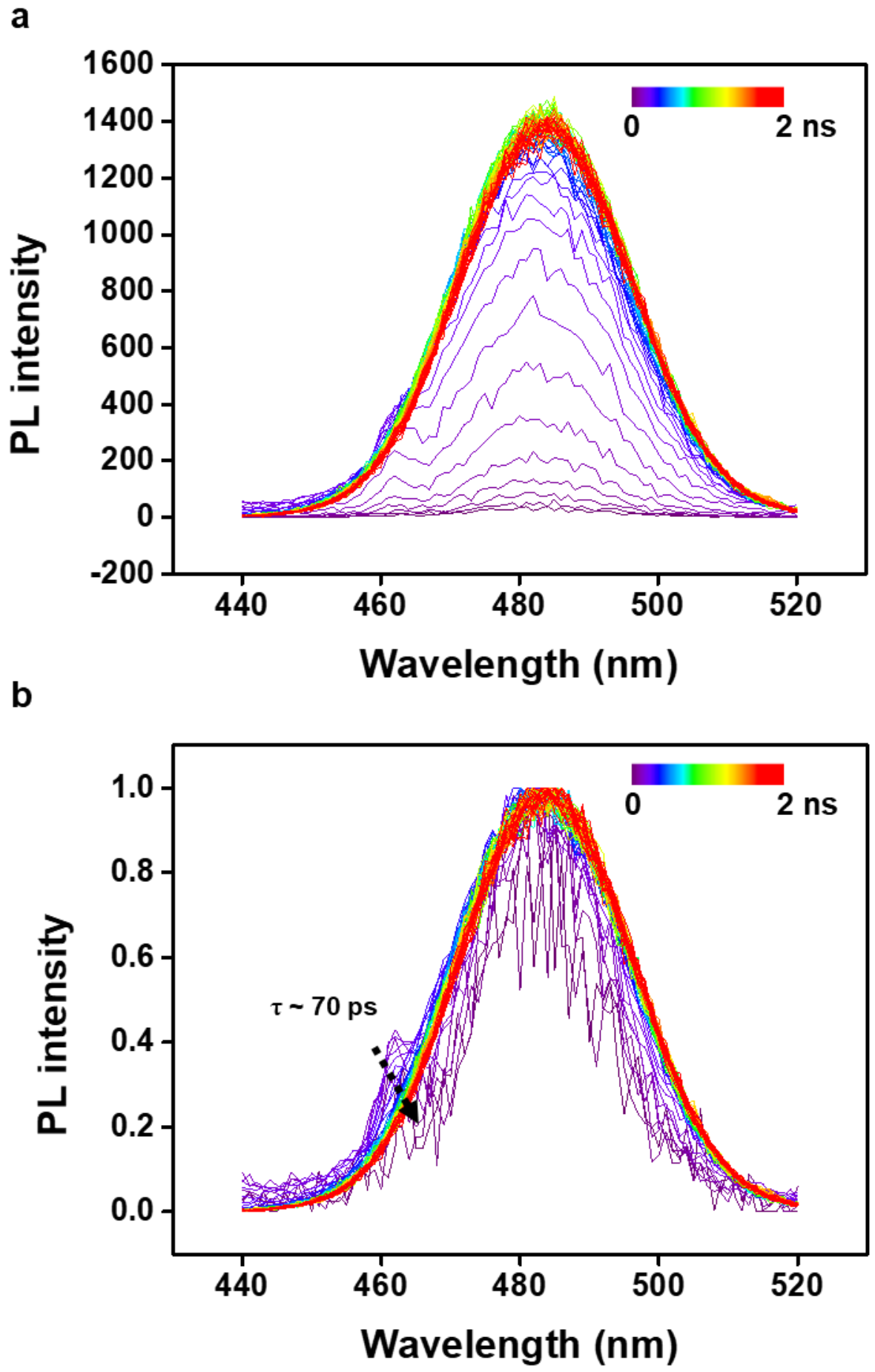

Figure S16. TRES of GCA from 0.0 to $2.0 \mathrm{~ns}$ with $0.025 \mathrm{~ns}$ gap. (a) unnormalized and (b) normalized PL intensity. 


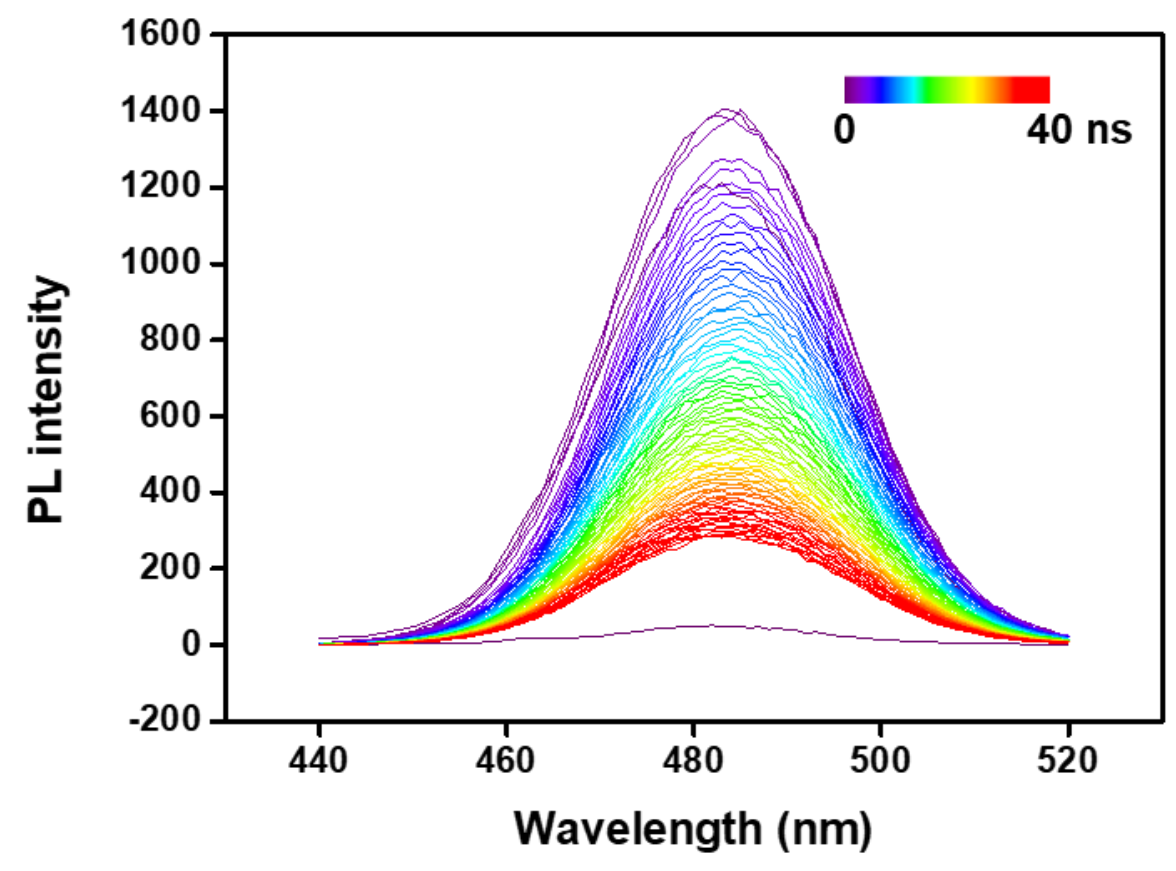

Figure S17. TRES of GCA from 0 to $40 \mathrm{~ns}$ with $0.5 \mathrm{~ns}$ gap. 
a

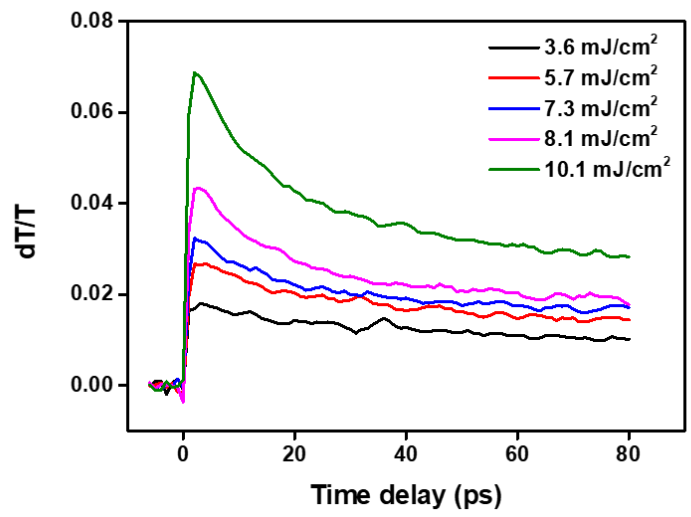

b

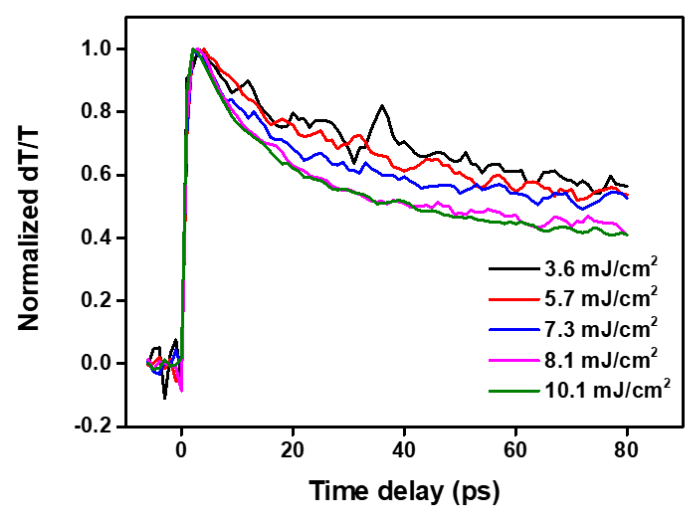

Figure S18. Pump-fluence dependence of GCA in TA at $460 \mathbf{n m}$ probe. (a) original and (b) normalized dT/T. Pump-fluence dependent TA shows the distinctive character of GCA compared to noble metal nanoclusters or nanoparticles.

Table S6. Fitting result of pump-fluence dependence of GCA in Figure S12a.

\begin{tabular}{|c|c|c|c|c|}
\hline Pump power & $\mathbf{A}_{1}$ & $\tau_{1}$ & $\mathbf{A}_{2}$ & $\tau_{2}$ \\
\hline $3.6 \mathrm{~mJ} / \mathrm{cm}^{2}$ & 0.00834 & $40.36 \mathrm{ps}$ & 0.00900 & $>10 \mathrm{~ns}$ \\
\hline $5.7 \mathrm{~mJ} / \mathrm{cm}^{2}$ & 0.01318 & $26.85 \mathrm{ps}$ & 0.01380 & $>10 \mathrm{~ns}$ \\
\hline $7.3 \mathrm{~mJ} / \mathrm{cm}^{2}$ & 0.01537 & 17.87 ps & 0.01688 & $>10 \mathrm{~ns}$ \\
\hline $8.1 \mathrm{~mJ} / \mathrm{cm}^{2}$ & 0.02191 & $13.33 \mathrm{ps}$ & 0.02273 & $424.68 \mathrm{ps}$ \\
\hline $10.1 \mathrm{~mJ} / \mathrm{cm}^{2}$ & 0.03090 & $11.63 \mathrm{ps}$ & 0.03912 & $232.54 \mathrm{ps}$ \\
\hline
\end{tabular}




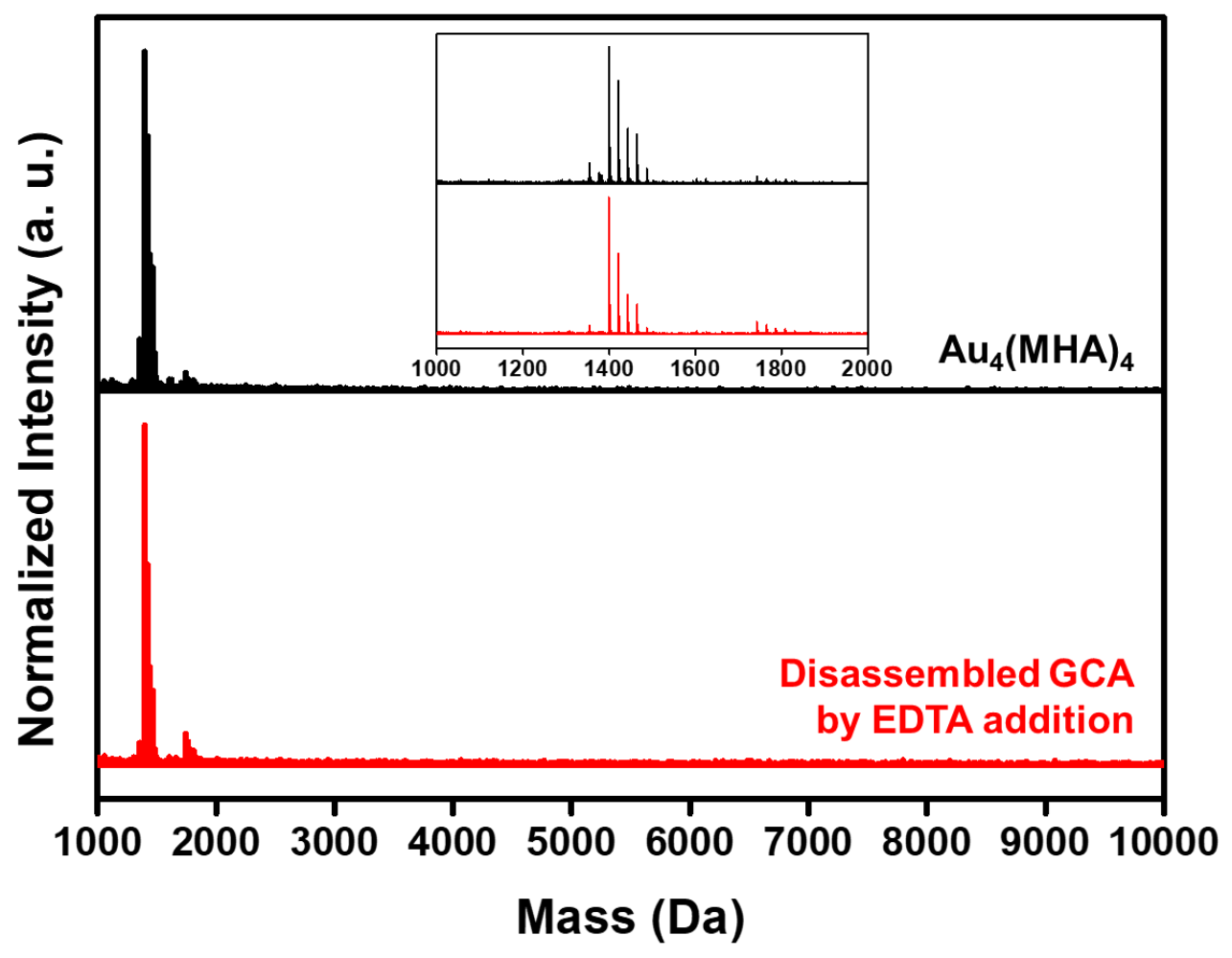

Figure S19. Mass spectra and amplified mass spectra (inset) of $\mathrm{Au}_{4}(\mathrm{MHA})_{4}$ (black) and disassembled GCA by EDTA addition (red). $\mathrm{Au}_{4}(\mathrm{MHA})_{4}$ structure is sustained after the disassembly process. 

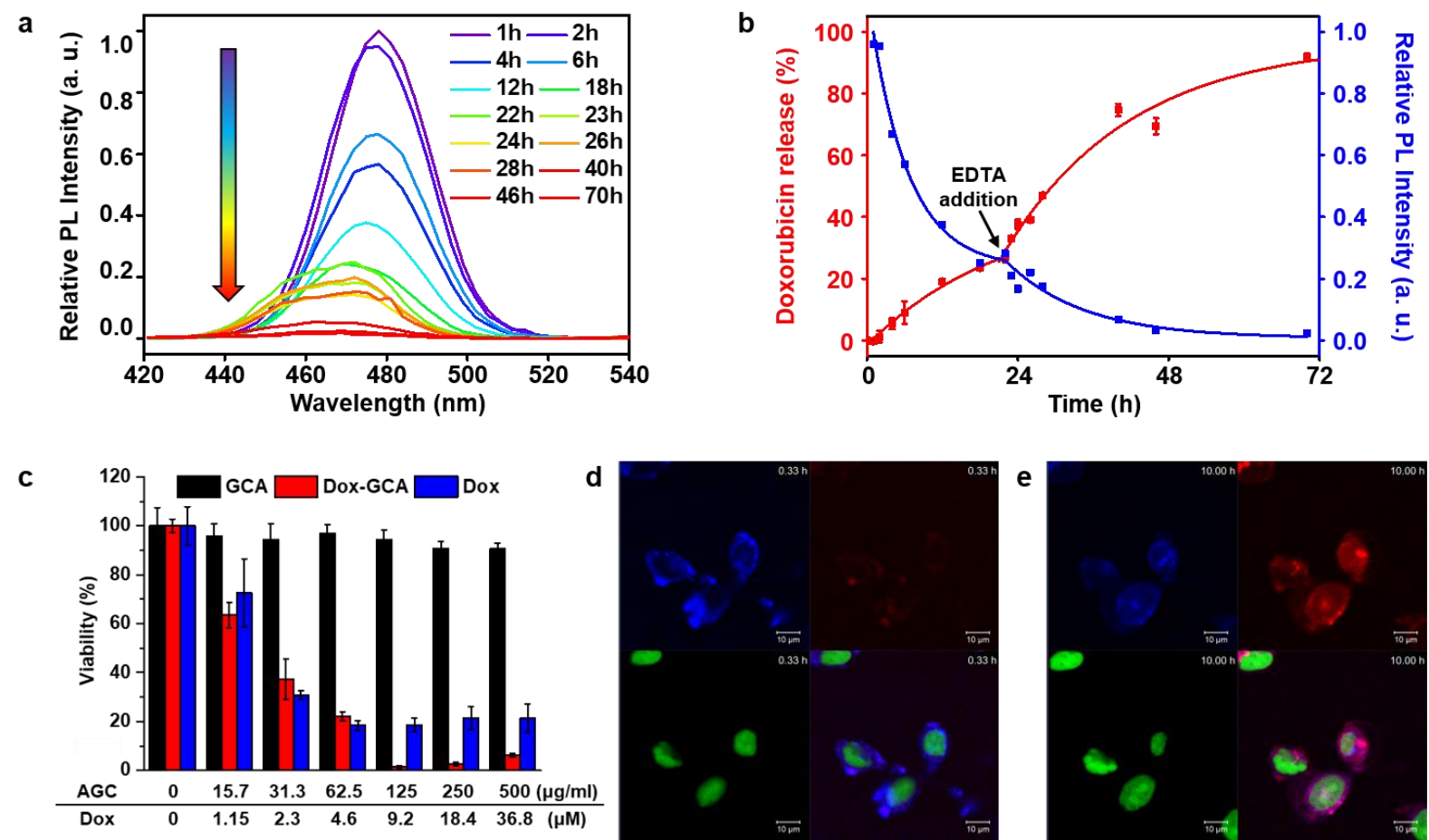

Figure S20. Demonstration of biomedical application of GCAs for trackable and biodegradable drug-delivery. (a) Time-dependent change of PL spectrum of doxorubicinloaded GCAs. (b) Release profiles of doxorubicin from Dox-GCA and the PL intensity of GCA during release. EDTA was added at $22 \mathrm{~h}$ to boost the release rate. (c) Evaluation of biocompatibility of GCA and anticancer effect of Dox-GCAs compared with free doxorubicin. (d, e) Confocal microscopy images of HeLa cells after the treatment of drug-loaded GCAs. 20 min after (d) and $10 \mathrm{~h}$ after the treatment. Each color notes the emission from GCAs (blue), doxorubicin (red) and Draq5 (green, nucleus-staining).

\section{Supporting References}

(1) Kellogg, R. E.; Bennett, R. G., Radiationless Intermolecular Energy Transfer. III. Determination of Phosphorescence Efficiencies. J. Chem. Phys. 1964, 41, 3042-3045.

(2) Ravel, B.; Newville, M., ATHENA, ARTEMIS, HEPHAESTUS: data analysis for X-ray absorption spectroscopy using IFEFFIT, J. Synchrotron Radiat. 2005, 12, 537-541.

(3) Zhou, M.; Zeng, C.; Chen, Y.; Zhao, S.; Sfeir, M. Y.; Zhu, M.; Jin, R., Evolution from the plasmon to exciton state in ligand-protected atomically precise gold nanoparticles, Nat. Commun. 2016, 7, 13240.

(4) Hartland, G. V., Optical studies of dynamics in noble metal nanostructures, Chem. Rev. 2011, $111,3858-3887$. 